\title{
Measurements of global and local effects of wave impact on a fixed platform deck

\author{
Nagi Abdussamie ${ }^{1}$, Roberto Ojeda ${ }^{1}$, Giles Thomas ${ }^{2}$, Walid Amin ${ }^{1}$
} \\ ${ }^{1}$ National Centre for Maritime Engineering and Hydrodynamics \\ Australian Maritime College, University of Tasmania, Launceston, TAS 7250, Australia \\ 2University College London, WC1E 6BT, UK
}

\begin{abstract}
This paper describes a series of model tests conducted to examine extreme wave events associated with tropical cyclonic conditions and their impacts on an offshore deck structure. Extreme waves of a representative cyclonic sea state were observed in a towing tank within long-crested irregular wave trains. Experimental results presented include global forces and localised slamming pressures acting on a rigidly mounted box-shaped deck, which represents a simplified topside structure of a tension leg platform (TLP). The effect of static set-down on the still-water air gap was investigated by applying an equivalent reduction for the deck clearance. It was found that a small reduction of $20 \mathrm{~mm}$ ( $2.5 \mathrm{~m}$ full scale) in the original deck clearance can lead to a doubly of the magnitude of the horizontal force and the vertical upward-directed force components, as well as significantly increase slamming pressures in many locations on the deck underside.
\end{abstract}

Keywords

Tropical cyclones; offshore platforms; wave-in-deck impact loads. 


\section{Introduction}

Current regulations used in the design of an offshore platform for a specific site ${ }^{1,2}$ require a minimum air gap of $1.5 \mathrm{~m}$ between the expected magnitude of a 100-year wave crest (including tide and storm surge) and the underside of the lowest deck of the platform. However, many reports have been published over the past decade detailing damage of the deck structure of offshore platforms owing to wave impacts. It is important to note that in many cases insufficient air gap has been reported to be one of the major reasons for damage sustained by offshore structures, e.g. the North Sea ${ }^{3}$, and the Gulf of Mexico ${ }^{4}$.

Damage to the structure or equipment can have costly economic and safety implications, as highlighted recently by McBride (2012). Consequently, there is a requirement by classification societies to ensure that an offshore facility can survive in extreme wave conditions caused by tropical cyclones or hurricanes with long return periods. Therefore slam events and the associated forces need to be accurately accounted for in the design stage 5. In addition a large proportion of Australian offshore petroleum installations have been in operation for 10 or more years ${ }^{6}$, and will therefore be soon subject to assessment for recertification and/or lifetime extension.

These assessments need to demonstrate that the structures will be able to withstand the environmental loads, including wave-in-deck loading, and be safe to remain in operation 7,8 .

It has been found that deck impacts occur more frequently than have been predicted using theoretical techniques ${ }^{9}$. This may be predominantly due to wave magnitudes being larger than expected, the actual air gap being smaller than anticipated and the resulting wave-in-deck impact forces being greater than predicted. These three factors are now discussed in more detail.

One of the key areas of interest for current and proposed offshore development is the North West Shelf (NWS) in Australia. This region is susceptible to tropical cyclones which can generate severe wave conditions ${ }^{10}$. For example, extreme wave heights were recorded at North Rankin platform off the Western Australia (WA) coast in 1989 during tropical cyclone Orson ${ }^{11}$; examination of the damage sustained by the base of the platform indicated that the platform had experienced impacts from waves with a height in excess of $20 \mathrm{~m}$. Buchan, Black

12 reported on the intensity of tropical cyclone Olivia which caused significant damage to oil and gas facilities in 
the NWS region. Metocean measurements taken during the storm indicate that the maximum wave heights were in the order of 15 to $20 \mathrm{~m}$. Such large (and steep) waves are greater in magnitude than the waves that these structures were designed for and would exceed the still-water air gap of many existing offshore platforms in the region of NWS.

It has been suggested that the $1.5 \mathrm{~m}$ air-gap safety margin recommended by the $21^{\text {st }}$ edition of API-RP-2A ${ }^{2}$ has provided an inconsistent level of reliability for structures ${ }^{13}$. As a result, the recommended crest values for the North Sea and Norwegian Sea have recently been increased ${ }^{14}$. New platforms will be designed with an air gap sufficient to avoid impacts with a $10^{-4}$ annual probability crest, or equivalent to 10,000 -year return period. The air gap for an offshore fixed or floating structure may be smaller in reality than it has been designed to be. For fixed offshore structures seabed subsidence or platform settlement due to reservoir compaction can over time reduce the original designed air gap exposing the structure to more severe wave impacts, as exemplified by the Ekofisk platform ${ }^{15,16}$. Likewise, for floating structures, a growth in operational weight or the flooding of compartments due to damage or sea level rise may lead to reduced air gaps ${ }^{17}$. Tension leg platforms (TLPs) can move downward "set-down" and are subject to rising sea levels, as well as subsidence of the bottom foundations. Any deck impact will therefore increase the tether tension due to an uplift force and then decrease the amount of tension as a result of downward force. In both directions, the tethers may experience an oscillatory sequence of snap loads and slackness. Consequently, the snap load that one or more tethers may experience is followed by a considerable negative force, i.e. suction force, which may exceed the initial pretension "zero-tension", thus imposing a high risk level on the whole system.

It is also important not to over design the offshore structure by obligating an excessive air gap since this can have severe implications for build and operational costs, and for floating structures in particular it will raise the centre of gravity and impair the payload performance.

In order to mitigate the potential effects of wave-in-deck impacts, a thorough understanding of wave induced loads is required. However, even though there is currently a large amount of research effort towards the computation of wave induced loads on ships and offshore structures, only few studies concentrate on wave 
loads from abnormal waves ${ }^{18}$. Several authors have conducted experimental investigations to estimate the wave-in-deck loading due to regular waves ${ }^{19,20}$, irregular waves ${ }^{21,22}$, and a combination of regular and irregular waves ${ }^{14}$. Despite this research, there is still considerable uncertainty about determining the magnitude of wave loads acting on structures located above the sea surface.

Particular questions remain. For example many researchers ${ }^{5,23}$ have concluded that "wave impact pressure is a bighly localised phenomenon in time and space". Therefore further investigation is required to assess the repeatability in the model experiment measurements of global forces and slamming pressures obtained by multiple test runs and test whether the mean value of pressure maxima obtained from multiple experimental runs can be used in the design of an offshore deck structure. Furthermore, more effort is required to determine appropriate signal processing procedures to identify the magnitude of the peak slamming force from the force measurement signals.

The objective of this work was to analyse the characteristics of extreme long-crested irregular waves and their impacts on a three-dimensional fixed deck structure using a series of model experiments. The model tests were conducted at the towing tank of the Australian Maritime College (AMC) to measure both the global and local force effects of extreme wave events on the deck structure. The horizontal and vertical wave-in-deck forces due to a number of extreme waves were simultaneously measured with localised pressures along and across the deck underside and the wave elevation in the vicinity of the model. The role of the dynamic response of the deck structure was identified by monitoring the acceleration components during wave impact tests. Besides, measurement repeatability were analysed and the observed variations in forces and pressures were discussed. The effect of the deck clearance reduction on the peak forces and impact pressures was also examined.

\section{Experimental investigation}

A series of model tests was conducted at the Australian Maritime College towing tank, which is $100 \mathrm{~m}$ long, $3.55 \mathrm{~m}$ wide and $1.5 \mathrm{~m}$ deep. It is equipped at one end with a hydraulically driven flap-type wavemaker and has an artificial beach located at the opposite end of the tank to minimise wave reflections. 


\section{Test model and instrumentation details}

The topside platform deck structure of a TLP was modelled using a flat horizontal box-shaped deck with external dimensions of length $(\mathrm{L})=608 \mathrm{~mm}$, breadth $(\mathrm{B})=608 \mathrm{~mm}$ and depth $(\mathrm{h})=210 \mathrm{~mm}$. The box dimensions were selected to represent, at a scale of 1:125, the $76 \mathrm{~m} \times 76 \mathrm{~m}$ centre to centre spacing between columns of the SNORRE-A tension leg platform (TLP) installed in 1992 at a water depth of $310 \mathrm{~m}$ in the Norwegian North Sea ${ }^{24}$.

The model deck was fabricated using a $10 \mathrm{~mm}$ thick aluminium plate for the bottom and $100 \mathrm{~mm} \times 25 \mathrm{~mm} \times$ $2.5 \mathrm{~mm}$ rectangular hollow sections (RHS) aluminium extrusions for the sides. Since the purpose of the testing was to measure wave slamming loads on the front and bottom faces of the deck structure without overtopping, a $100 \mathrm{~mm}$ high acrylic sheet was installed on top of the RHS to prevent water from splashing onto the internal deck space as shown in Figure 1. The deck was elevated above the water surface at a distance representing the still-water air gap i.e. deck clearance. The effect of sit-down was examined by reducing the original deck clearance.

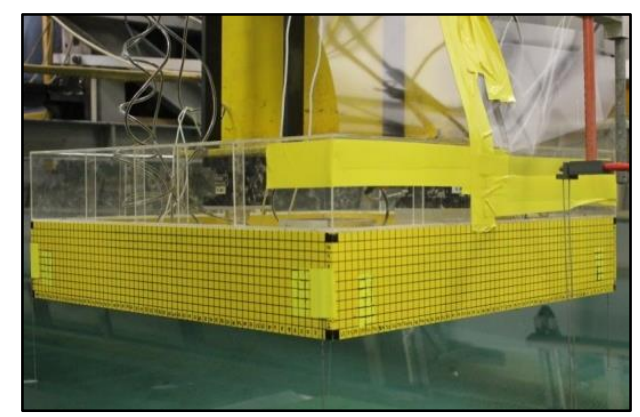

Figure 1. Photograph of the deck model positioned above the water surface.

Recent experimental studies ${ }^{14,25}$ have shown that a considerable dynamic response in force measurements is introduced when a fixed deck model is directly attached to a towing tank carriage. To minimise this undesired effect the stiffness and rigidity of the system was improved by attaching the model to a $4500 \mathrm{~mm}$ long steel Hbeam $(334 \mathrm{~mm} \times 170 \mathrm{~mm} \times 6 / 11 \mathrm{~mm})$ mounted on the tank rails and placed $15 \mathrm{~m}$ away from the wavemaker as shown in Figure 2. The remaining $85 \mathrm{~m}$ of towing tank allowed for sufficiently long run times without 
interference from reflected waves travelling back up the tank ${ }^{26}$. The deck model was then supported by two load cells (LC1 and LC2) connected to a vertical $510 \mathrm{~mm}$ long I-beam (360 mm x $170 \mathrm{~mm}$ x 6/10 mm) suspended from the H-beam.

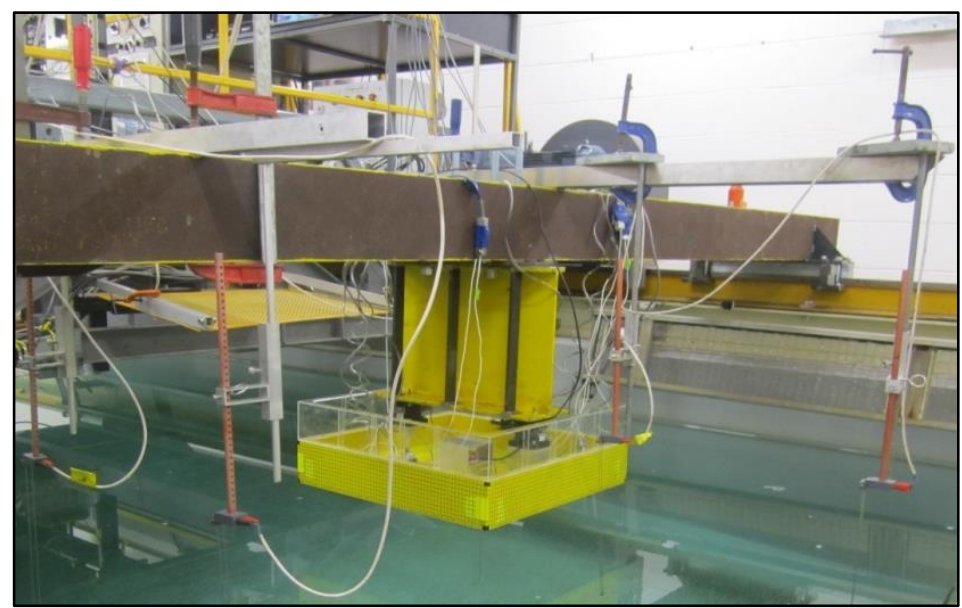

Figure 2. Experimental setup showing the deck structure attached to an I beam under the $\mathrm{H}$ beam across the towing tank, with WP2 - WP5 in the vicinity of the model (wave propagating from right to left).

\section{Deck clearance}

Wave-in-deck impact events occur when the dynamic air gap reduces to zero, as a result of either a reduction

in the static air gap i.e. deck clearance or when an extreme wave exceeds the deck clearance. Three deck clearances were nominated based on the platform's loading conditions, as shown in Figure 3 at model scale with the z-coordinate vertical and positive upward. Scenario 1 is equivalent to the operating draft of SNORREA at normal condition. Scenarios 2 and 3 were designated to investigate the effect of static set-down (or increase in the platform's draft) on the magnitude of wave-in-deck forces. Such an increase in the platform's operating draft can be caused by tension increase in the tethers. The resulting deck clearances measured from still water level to the deck underside are $120 \mathrm{~mm}$ (15 m full scale), $110 \mathrm{~mm}(13.75 \mathrm{~m}$ full scale) and $100 \mathrm{~mm}$ (12.5 m full scale). The $10 \mathrm{~mm}$ reduction in deck clearance, which is equivalent to $1.25 \mathrm{~m}$ at full scale, could realistically occur during a platform's lifetime due to platform settlement, set-down or sea level rise ${ }^{15,27}$. It is assumed that the deck's underside will be in a flat position in relation to the water surface. 
(a)

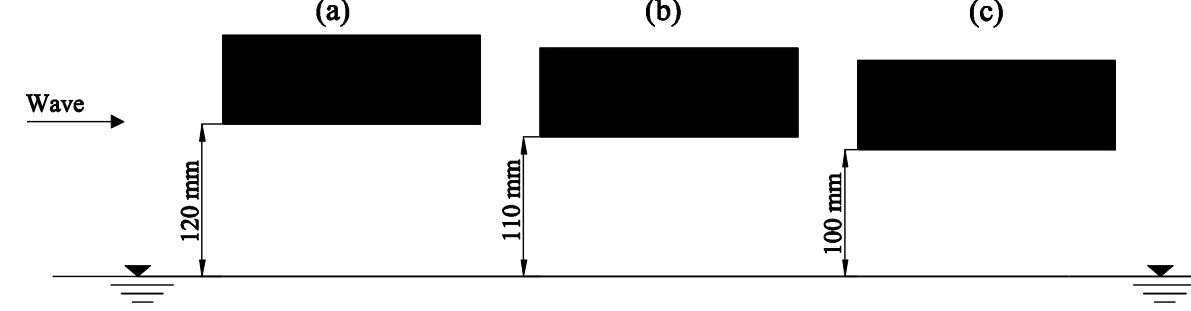

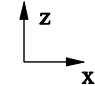

Figure 3. Profile views showing the three deck clearances measured from the still-water line: (a) original deck clearance (scenario 1); (b) scenario 2 and (c) scenario 3.

The deck clearance adjustment was performed by moving the deck up and down using four finely threaded rods and nuts, as illustrated in Figure 4, and connecting both beams (H-beam and I-beam) so that the deck alignment in the $x y$ plane relative to the water surface could be controlled.

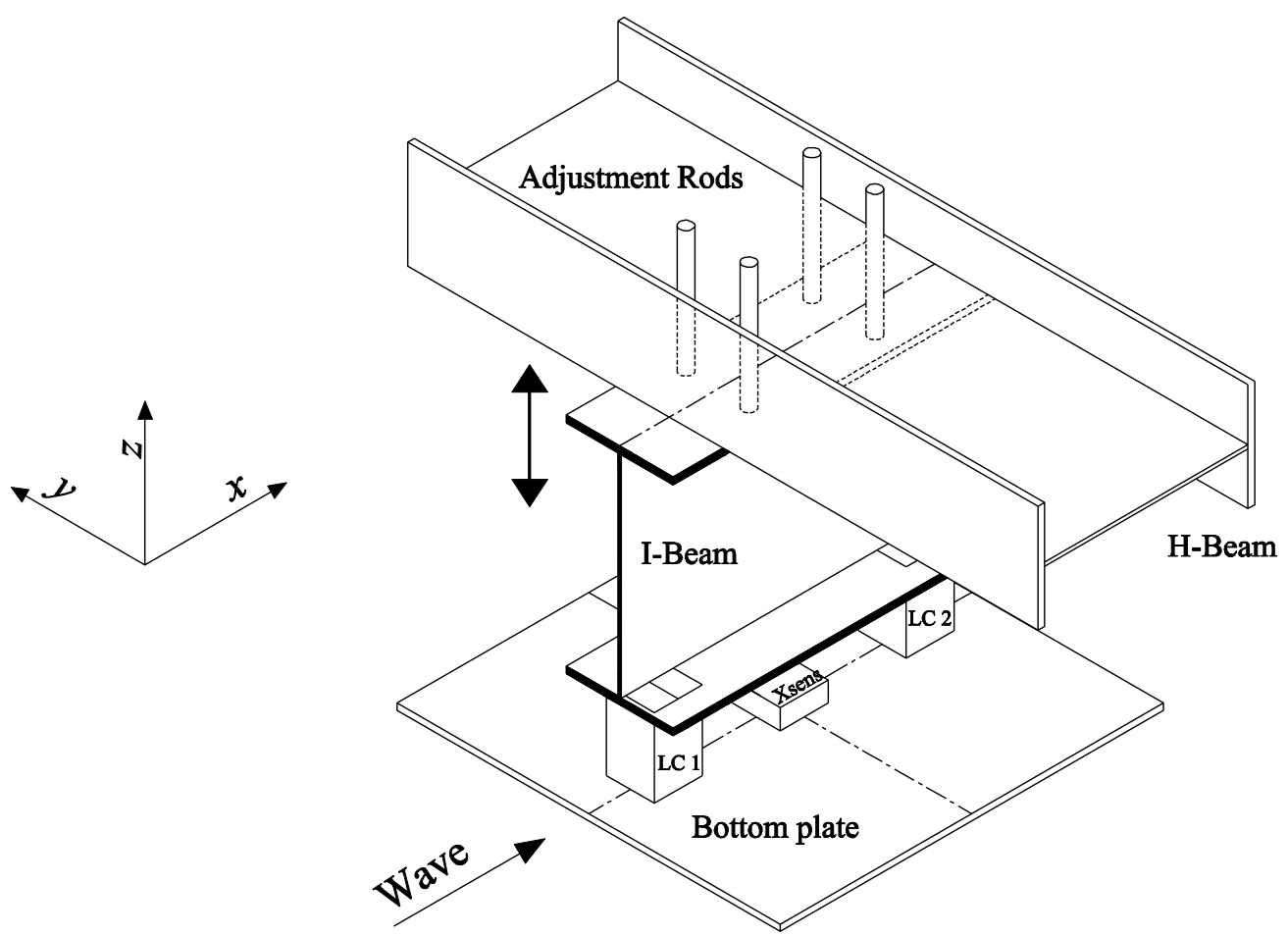

Figure 4. Isometric view of model attachment and method of adjustment of deck clearance.

\section{Measurement of wave elevation}

Wave surface elevations were measured using five capacitance-type wave probes; denoted as WP in Figure 5.

The location of each wave probe is presented in Table 1 defined from the origin point located at the model's 
geometric centroid. During all tank experiments a constant water depth of $1.5 \mathrm{~m}$ was maintained. The wave height of incoming/incident waves, travelling in positive $x$-direction along the tank, was measured by WP1 and WP2.

Before the impact tests were conducted, the change in crest height through the test section was investigated by using WP3 through WP5 without the deck structure in place. During the impact tests the wave height at the leading edge (LE) and trailing edge (TE) of the deck were simultaneously measured by WP4 and WP5 so that the disturbed wave profile due to the presence of the deck could be recorded. Meanwhile the undisturbed profile of the incoming wave at the centreline in front of the deck was measured by WP2.

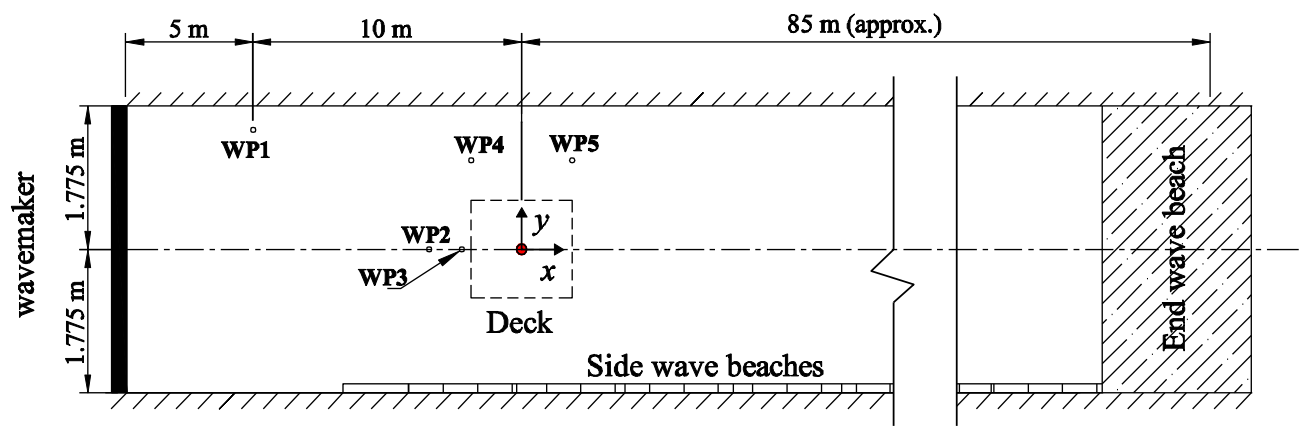

Figure 5. Schematic diagram (plan view) of the towing tank [not to scale].

Table 1. Location of wave probes with respect to the model centroid.

\begin{tabular}{|c|c|}
\hline Wave probe (WP) & Location $(x, y)[\mathrm{m}]$ \\
\hline 1 & $(-10,0.5)$ \\
\hline 2 & $(-1.04,0.0)$ \\
\hline 3 & $(-0.404,0.0)$ \\
\hline 4 & $(-0.304,1.20)$ \\
\hline 5 & $(0.304,1.20)$ \\
\hline
\end{tabular}

\section{Measurements of wave-in-deck loads}

In this work, both global and local effects of wave-in-deck impact loading were investigated. Two load cells were used to measure the global forces generated due to the impact of the wave crest against the deck structure. The layout of the two AMTI MC3A-100 load cells, denoted by LC1 and LC2, is illustrated in Figure 6. Each load cell has a square base of $76 \mathrm{~mm} \times 76 \mathrm{~mm}$ and they were connected to the deck of the box model using a 
hinge for LC1 and a slider for LC2. This meant that the total vertical force, $F_{z}$, was measured by both load cells whilst the horizontal force, $F_{x}$, was measured by the forward load cell LC1 only. In order to monitor the deck acceleration components, an MTi-30 Xsens accelerometer was installed at the middle of the bottom plate.

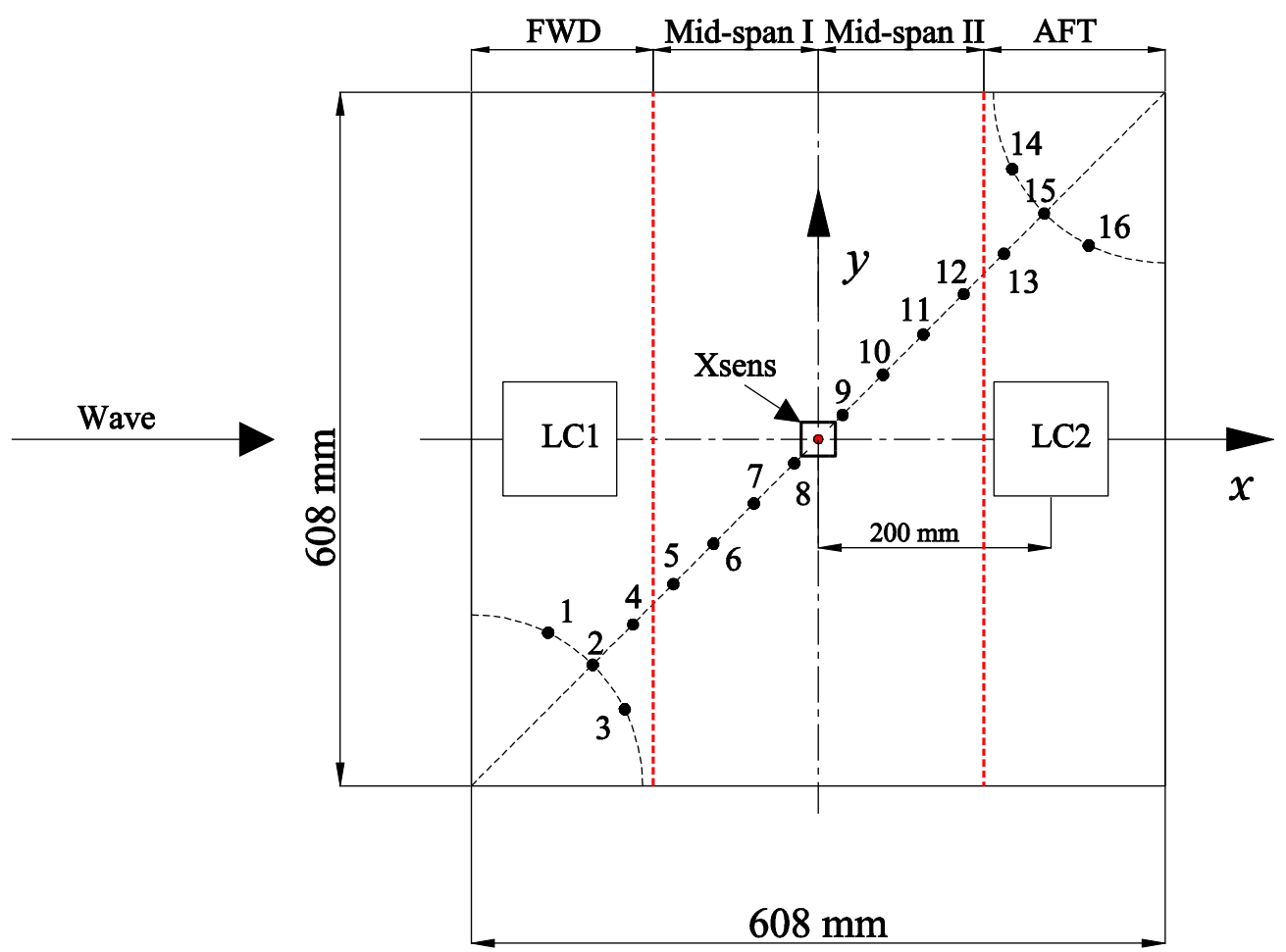

LE

Figure 6. Distribution of pressure transducers and load cells on the bottom plate [not to scale].

The localised slamming pressures were measured using sixteen piezoresistive pressure transducers (five Endevco 8510C-50, three Endevco 8510B-2 and eight Measurex MRV21-0.5). These pressure transducers have a high resonance frequency, making them suitable for the measurement of slamming pressures ${ }^{28}$. The tip of each transducer, which has a diameter of approximately $4 \mathrm{~mm}$, was mounted flush with the underside of the deck. As can be seen in Figure 6 and Table 2, the pressure transducers (denoted as PT) were placed along the diagonal of the bottom plate. PT\#1 was located close to the leading edge (LE) whilst PT\#16 was located near the trailing edge (TE). PT\#3 and PT\#14 were installed to measure slamming pressures near the deck edges; 
especially to try and capture the aeration process that may take place. The remaining pressure transducers, PT\#1 through PT\#15, were diagonally arranged so that pressure distribution in the $x y$ plane could be obtained. The arrangement results in four regions fitted with four pressure transducers each (Table 3) such that pressure analysis can be done on the basis of an area rather than on a discrete point. A sampling frequency of $20 \mathrm{kHz}$ was chosen for all channels (including wave probes) in order to capture the short-duration slamming pressures 29. This high sampling frequency, with a total of twenty four channels being recorded, limited the data acquisition time to approximately $40 \mathrm{~s}$ due to software memory constraints.

Table 2. Specifications and coordinates of pressure transducers (PT).

\begin{tabular}{|c|c|c|c|c|}
\hline PT\# & Model & $\begin{array}{c}\text { Sensitivity } \\
{[\mathrm{mV} / \mathrm{kPa}]}\end{array}$ & $\begin{array}{c}\text { Range } \\
{[\mathrm{kPa}]}\end{array}$ & $\begin{array}{c}\text { Location }(x, y) \text { relative to model centroid } \\
{[\mathrm{mm}]}\end{array}$ \\
\hline 1 & $8510 \mathrm{~B}-2$ & 16.65 & $0-13.8$ & $(-236.9,-169.8)$ \\
\hline 2 & $8510 \mathrm{~B}-2$ & 19.095 & $0-13.8$ & $(-197.9,-197.9)$ \\
\hline 3 & MRV21-0.5 & 1.038 & $0-50$ & $(-169.8,-236.9)$ \\
\hline 4 & MRV21-0.5 & 1.042 & $0-50$ & $(-162.6,-162.6)$ \\
\hline 5 & MRV21-0.5 & 1.036 & $0-50$ & $(-127.2,-127.2)$ \\
\hline 6 & $8510 C-50$ & 0.662 & $0-344$ & $(-91.9,-91.9)$ \\
\hline 7 & MRV21-0.5 & 1.051 & $0-50$ & $(-56.5,-56.5)$ \\
\hline 8 & $8510 C-50$ & 0.67 & $0-344$ & $(21.2,-21.2)$ \\
\hline 9 & $8510 C-50$ & 0.731 & $0-344$ & $(56.5,56.5)$ \\
\hline 10 & MRV21-0.5 & 1.035 & $0-50$ & $(91.9,91.9)$ \\
\hline 11 & $8510 C-50$ & 0.701 & $0-344$ & $(127.2,127.2)$ \\
\hline 12 & MRV21-0.5 & 1.11 & $0-50$ & $(162.6,162.6)$ \\
\hline 13 & MRV21-0.5 & 1.021 & $0-50$ & $(169.8,236.9)$ \\
\hline 14 & MRV21-0.5 & 1.091 & $0-50$ & $(197.9,197.9)$ \\
\hline 15 & $8510 B-2$ & 17.5 & $0-13.8$ & $(236.9,169.8)$ \\
\hline 16 & $8510 C-50$ & 0.665 & $0-344$ & \\
\hline
\end{tabular}


Table 3. The examined regions along the bottom plate.

\begin{tabular}{|c|c|}
\hline Region & Pressure Transducers (PT) \\
\hline FWD - LE & $1,2,3,4$ \\
\hline Mid-span I & $5,6,7,8$ \\
\hline Mid-span II & $9,10,11,12$ \\
\hline AFT - TE & $13,14,15,16$ \\
\hline
\end{tabular}

\section{Experimental procedure}

The experiments were conducted using a combination of the following procedures:

- Wave calibration tests - carried out to identify the extreme waves within long-crested irregular wave trains without the model in-place.

- Free oscillation tests - to find the natural frequencies of the complete test system when subjected to free oscillation tests in air and in water.

- Wave impact tests - to measure the impact wave forces and localised slamming pressures. In addition the deck accelerations were monitored to identify the structural dynamic response and its effect on the force magnitudes by estimating the inertial force contribution in the load cell responses.

\section{Wave calibration tests}

The wave calibration tests were conducted by measuring the wave elevation profile, using five wave probes spread longitudinally down the tank, whilst running long-crested irregular waves without the deck model in place. The tank length and absence of the deck model instrumentation allowed for long data acquisition times with the wave probes being sampled at $200 \mathrm{~Hz}$. Three long-crested irregular wave trains, with a duration of 120 s each, were generated. The wave trains were representative of cyclonic conditions for a 10,000-year return period at the NWS of Australia with a significant wave height, $H_{s}$, of $177 \mathrm{~mm}(22.125 \mathrm{~m}$ full scale $)$ and a peak wave period, $T_{p}$, of $1.52 \mathrm{~s}(17.0 \mathrm{~s}$ full scale). The JONSWAP spectrum with a peak shape parameter $\gamma=1.0$, which in this case is identical to the Pierson-Moskowitz (PM) spectrum ${ }^{29}$, was used to synthesise short-time wave trains using the towing tank wavemaker. 
Since a small change in crest height can lead to a considerable variation in the associated wave impact forces and slamming pressures, accurate measurement of the wave height was critical. Consequently, the wave crests of each wave event were identified from the measured wave elevation time histories with and without the deck structure in-place (at different deck clearances, $a_{0}$ ). Since the wave front is initially measured at the leading edge, when it comes in contact with the deck surface, WP4 time histories were used to identify wave characteristics of the wave events of interest. An example is presented in Figure 7 where two wave events in a single wave train can be identified by analysing the wave elevation time histories of WP4 (at the LE). This wave train contains WE1 observed at time $=0.0$ to $2.0 \mathrm{~s}$ and WE2 at time $=12.0$ to $13.5 \mathrm{~s}$. Such extreme waves, approximately $27.5 \mathrm{~m}$ to $31.0 \mathrm{~m}$ high at full scale, can indeed occur in severe sea states. For instance similar steep waves were measured by three wave radars on the Macro Polo tension leg platform during hurricane Rita in the Gulf of Mexico ${ }^{30}$.

It can be observed that the generated waves had good repeatability using multiple runs at different values of $\mathrm{a}_{0}$, with only a very minimal disturbance on crest height of WE1 seen in Figure 7 (a) due to the presence of the deck structure. Nevertheless, the crest elevation of WE2 was heightened by approximately 6\% for all deck clearances when the deck was present, as shown in Figure 7 (b). Therefore the wave crest measured simultaneously with wave impact forces and slamming pressures was used when investigating the relationship between the impacting waves and the associated wave-in-deck loads. 

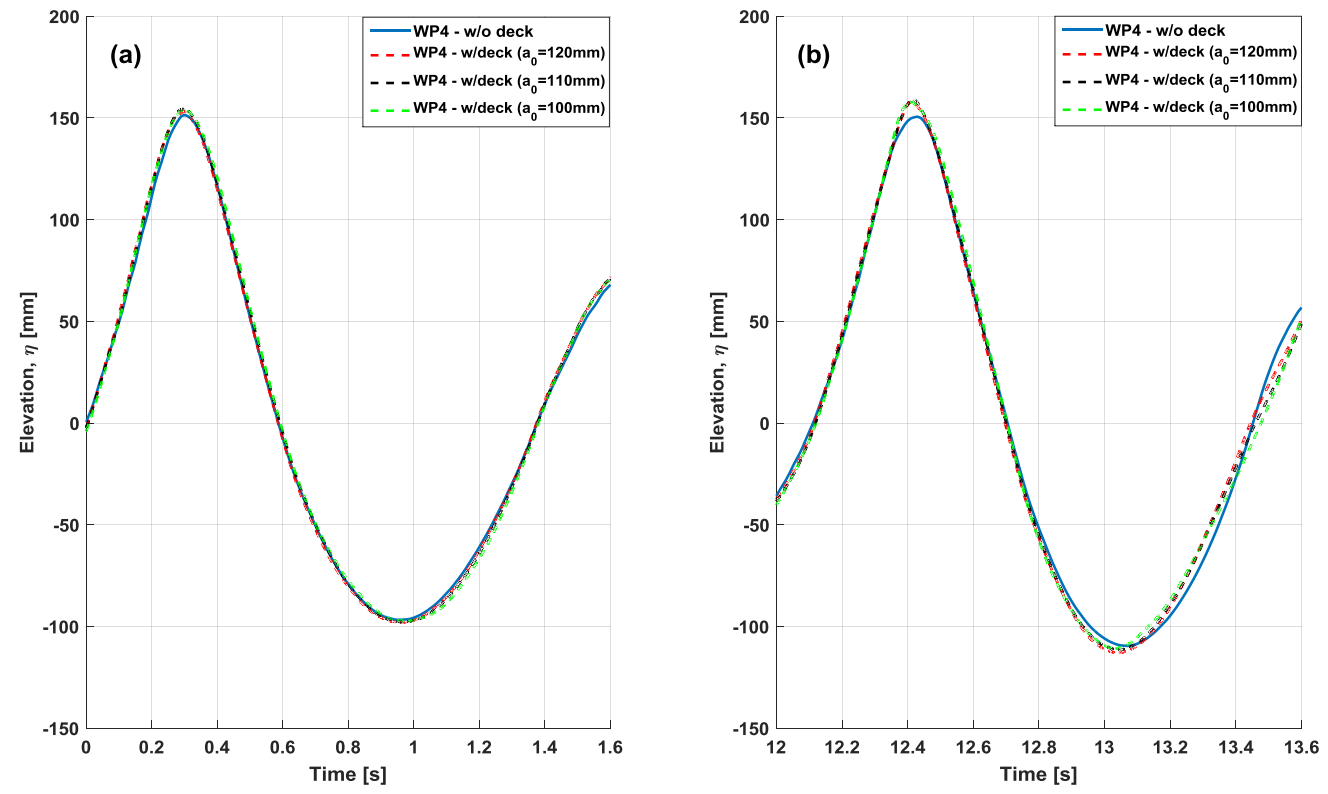

Figure 7. Time history of wave elevation at the leading edge measured by WP4 with and without the deck structure: (a) wave event 1 ; (b) wave event 2 .

shows a fair match between the measured wave elevation of WE1 at the leading edge (while the deck in place) by WP4 with the theoretical one obtained based on Stokes second and fifth orders was achieved. However, the theoretical wave elevation failed to reproduce the non-linear behaviour at both wave crest and trough, underestimating the crest height and overestimating the trough amplitude. Besides, in terms of time-evolution both Stokes orders were found to be approximately identical but wider/broader than the measured WE1. 


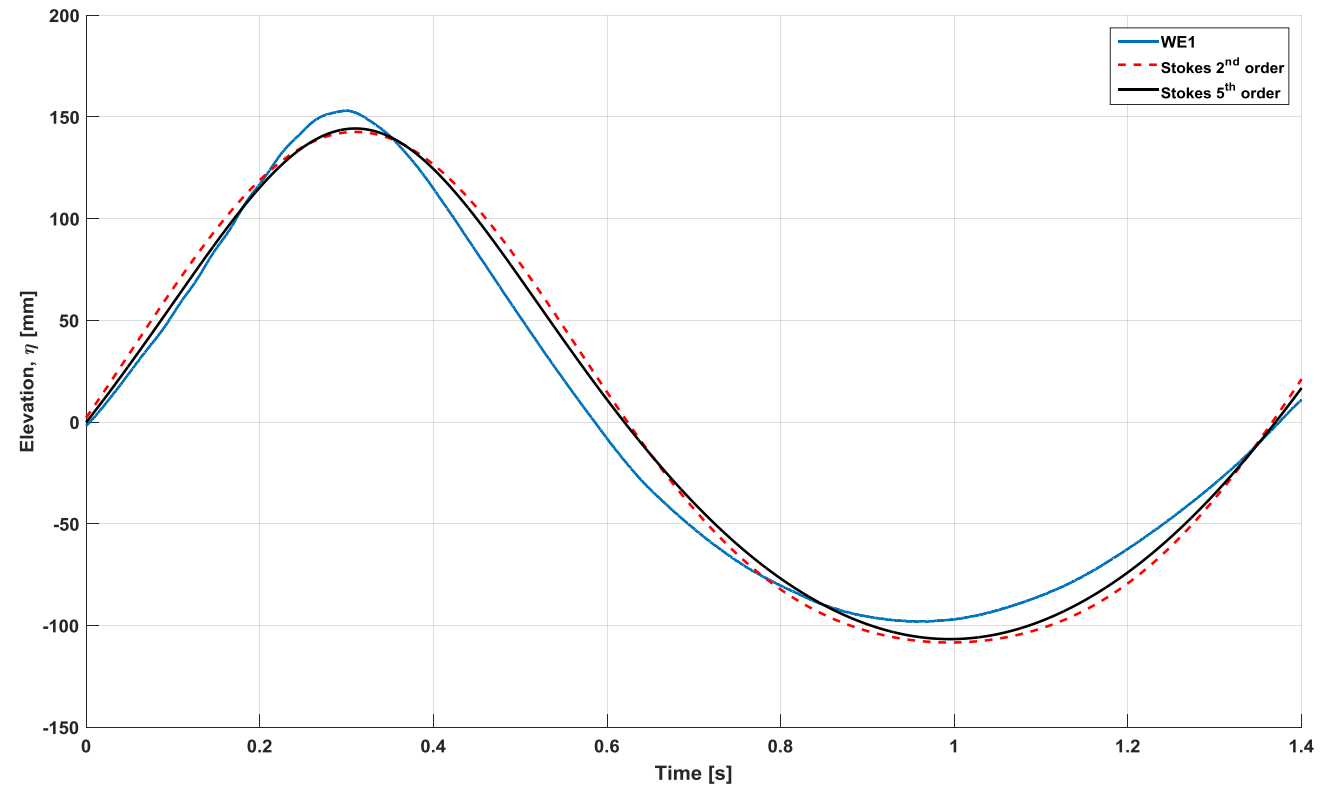

Figure 8. Time history of WE1 measured by WP4 and compared to Stokes wave theory.

The wave calibration procedure identified a total of 12 wave events (WE), which were then used in the wave impact tests. Each wave event is defined by wave height $(H)$, wave crest height $\left(\eta_{c}\right)$ and wave period $\left(T_{z}\right)$ as summarised in Table 4. The zero up-crossing method ${ }^{29}$ was employed to estimate such parameters (Figure 9). In order to combine the effect of wave height and its period, the wave steepness, $\mathrm{S}$, of each wave event is introduced using $\mathrm{S}=\mathrm{H} / \lambda$ in which $\lambda$ is the wavelength estimated from the dispersion relationship ${ }^{29}$. The maximum wave steepness of the identified wave events was found to be approximately 0.10 (WE5) i.e. nonbreaking wave conditions. The wave skewness $\left(\eta_{c} / H\right), \beta$, is also introduced for each wave event. The phase celerity, $\mathrm{C}$, was estimated by $\lambda / \mathrm{T}_{\mathrm{z}}$ for each WE so that the resulting impact pressure could be related to the associated dynamic pressure $\left(0.5 \rho \mathrm{C}^{2}\right)$. In addition, since the magnitude of the peak horizontal force depends on the associated wave velocity, $\mathrm{u}$, in $x$-direction at the wave crest, the later was estimated using the Stokes second order wave kinematics ${ }^{29}$, as given in Table 4 . 
Studying the information in Table 4, the crest height, $\eta_{c}$, of both WE7 and WE9 suggests that no impact can occur when the deck is elevated above such a height ( $\mathrm{a}_{0}=120 \mathrm{~mm}$ or $\left.\mathrm{a}_{0}=110 \mathrm{~mm}\right)$. However, it was observed that while WE7 and WE9 have a small crest height at the LE (WP4), both wave events hit the deck bottom at the rear section as the wave crest becomes larger as noted in the time history of WP5.

Table 4. Wave events (WE) and their parameters.

\begin{tabular}{|c|c|c|c|c|c|c|c|c|}
\hline $\mathrm{WE}$ & $\mathrm{H}[\mathrm{mm}]$ & $\eta_{\mathrm{c}}[\mathrm{mm}]$ & $\mathrm{T}_{z}[\mathrm{~s}]$ & $\lambda[\mathrm{m}]$ & $\mathrm{C}[\mathrm{m} / \mathrm{s}]$ & $\mathrm{u}[\mathrm{m} / \mathrm{s}]$ & $\mathrm{S}[-]$ & $\beta[-]$ \\
\hline 1 & 251 & 153 & 1.37 & 2.92 & 2.13 & 0.803 & 0.086 & 0.61 \\
\hline 2 & 271 & 158 & 1.33 & 2.76 & 2.08 & 0.92 & 0.098 & 0.58 \\
\hline 3 & 213 & 129 & 1.51 & 3.53 & 2.34 & 0.56 & 0.060 & 0.61 \\
\hline 4 & 190 & 138 & 1.74 & 4.58 & 2.63 & 0.42 & 0.041 & 0.73 \\
\hline 5 & 242 & 163 & 1.23 & 2.36 & 1.92 & 0.95 & 0.103 & 0.67 \\
\hline 6 & 198 & 130 & 1.24 & 2.4 & 1.94 & 0.71 & 0.083 & 0.66 \\
\hline 7 & 184 & 112 & 1.2 & 2.25 & 1.88 & 0.66 & 0.082 & 0.61 \\
\hline 8 & 249 & 166 & 1.49 & 3.44 & 2.31 & 0.72 & 0.072 & 0.67 \\
\hline 9 & 157 & 90 & 1.95 & 5.55 & 2.85 & 0.29 & 0.028 & 0.57 \\
\hline 10 & 168 & 118 & 1.2 & 2.25 & 1.88 & 0.61 & 0.075 & 0.70 \\
\hline 11 & 190 & 112 & 1.11 & 1.92 & 1.73 & 0.78 & 0.10 & 0.59 \\
\hline 12 & 154 & 104 & 1.78 & 4.76 & 2.67 & 0.32 & 0.032 & 0.68 \\
\hline
\end{tabular}




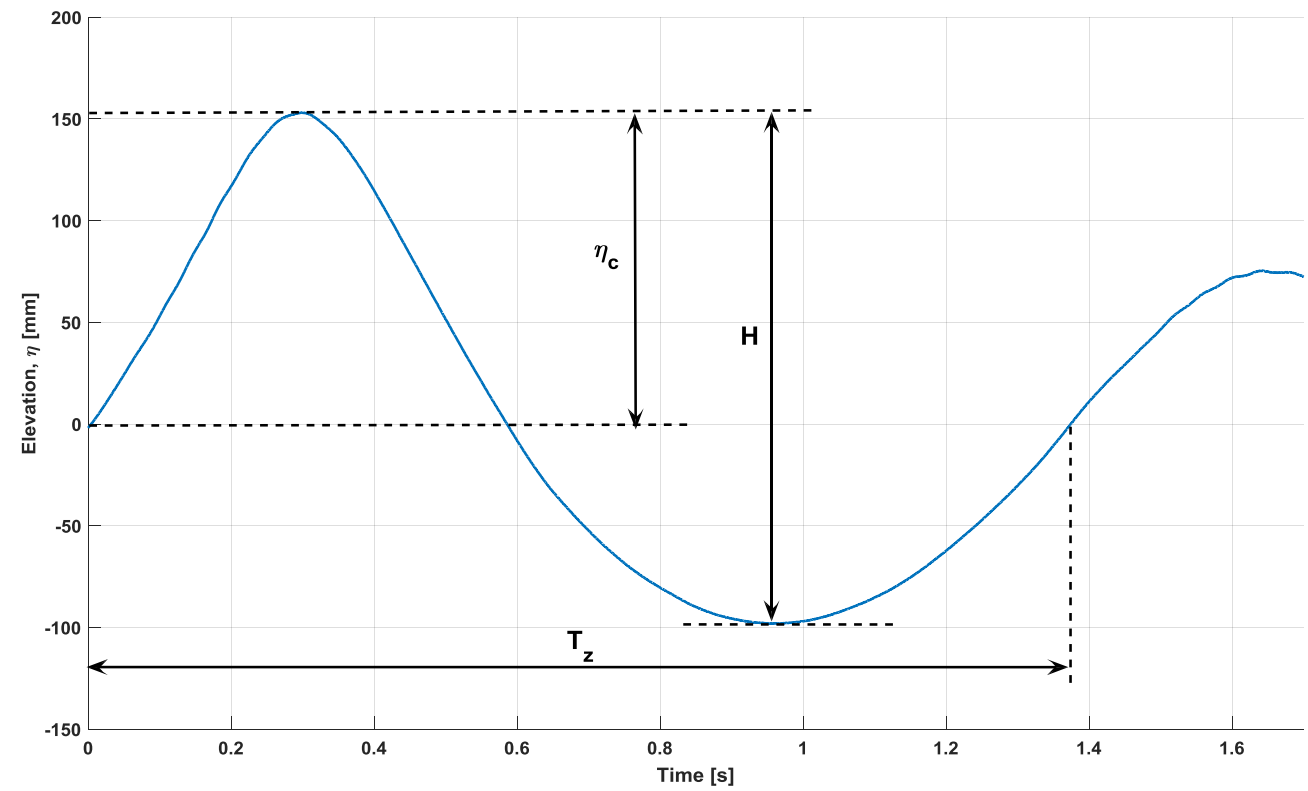

Figure 9. Estimated wave parameters of WE1 using the zero up-crossing method applied to WP4 time histories.

These wave parameters can be obtained graphically, as shown in Figure 10, by mapping the wave event along subplots (a), (b) and (c) and using $H_{s}=177 \mathrm{~mm}$ and $\mathrm{T}_{\mathrm{p}}=1.52 \mathrm{~s}$. The ratio of $\mathrm{H} / \mathrm{H}_{\mathrm{s}}$ for the observed wave events ranges from 0.87 (WE12) to 1.53 (WE2), whilst the wave skewness $\left(\beta=\eta_{c} / H\right)$ was found to be between 0.57 (WE9) and 0.73 (WE4). For $\mathrm{T}_{\mathrm{z}} / \mathrm{T}_{\mathrm{p}}$ ratio, it was estimated to be within 0.73 (WE11) and 1.28 (WE9). 

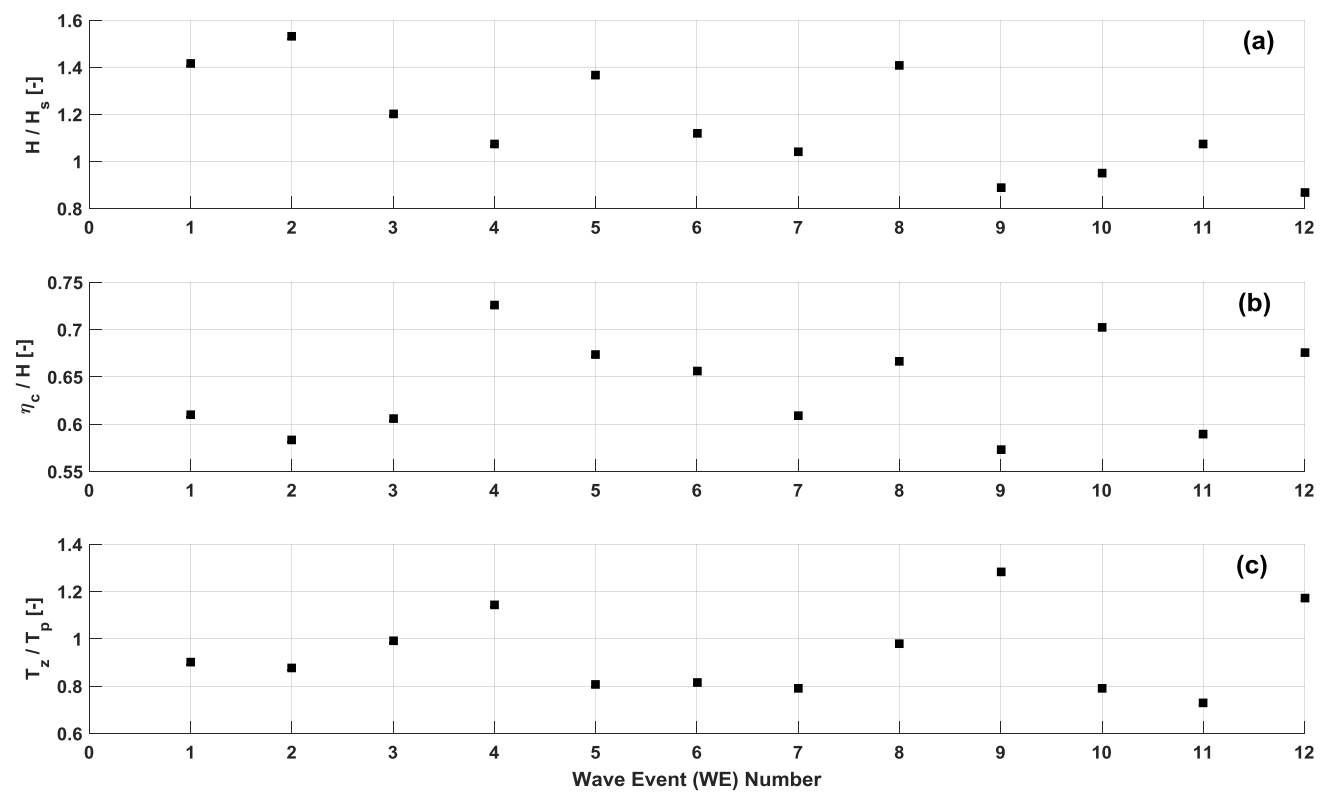

Figure 10. Wave parameters of measured extreme wave events (WE): (a) wave height ratio (H/Hs); (b) wave skewness, $\beta$ $=\eta_{\mathrm{c}} / \mathrm{H} ;(\mathrm{c})$ wave period ratio $\mathrm{T}_{z} / \mathrm{T}_{\mathrm{p}}$.

\section{Free oscillation tests}

Once the instrumented model was attached to the heavy beam mounted on the tank rails, the full testing assembly (deck model, instruments and force supports) was subjected to a series of oscillatory decay tests. Dry and wet free oscillation tests were performed in order to identify the natural frequency of the system. By obtaining the lowest natural frequency of the system in $x$ - and z-direction, the force contribution into the load cell signals due to the system's dynamics may be identified. The dry free oscillation tests were conducted with the deck positioned above the water surface, whereas the wet free oscillation tests were executed by lowering the model such that the deck underside was slightly touching the water surface. The free oscillation traces were measured by means of the load cells and the MTi-30 Xsens accelerometer. The lowest natural frequencies (denoted as $f_{\mathrm{n}}$ ) obtained in the dry and wet free oscillation tests are summarised in Table 5, based on time traces measured by both load cells and accelerometer.

Table 5. The lowest natural frequencies, $f_{\mathrm{n}},(\mathrm{Hz})$ obtained from free oscillation tests in air and in water.

\begin{tabular}{|l|l|l|l|}
\hline & & $f_{\mathrm{n}}$ in $x$-direction $(\mathrm{Hz})$ & $f_{\mathrm{n}}$ in $z$-direction $(\mathrm{Hz})$ \\
\hline
\end{tabular}




\begin{tabular}{|c|c|c|c|c|c|}
\hline $\begin{array}{c}\text { Decay } \\
\text { test }\end{array}$ & $\begin{array}{c}\text { Medium } \\
\text { (type) }\end{array}$ & Accelerometer & Load cell & Accelerometer & Load cell \\
\hline 1 & Air (dry) & 9.76 & 9.714 & 16.08 & 16.0 \\
\hline 2 & Water (wet) & 10.2 & 10.18 & 14.66 & 14.5 \\
\hline
\end{tabular}

A comparison between the results for the dry and wet free oscillation tests in $x$-direction is made in the frequency domain using Fast Fourier Transform (FFT), as shown in Figure 11 (a). The second and the third modal frequencies obtained from the dry test $(16.0 \mathrm{~Hz}$ and $21.8 \mathrm{~Hz})$ are not present when the bottom plate of the deck is aligned on the water surface, due to the contribution of the relatively small added mass and viscous damping to the system in the longitudinal direction ( $x$-direction). As shown in Figure 11 (b), the effect of water surrounding the bottom plate is more pronounced in the $₹$-direction than in $x$-direction. The lowest natural frequency observed while the deck was tested in air $(16.0 \mathrm{~Hz})$ was found to reduce to $14.5 \mathrm{~Hz}$.

It can be appreciated that the natural frequencies of the system (in both the $x$ and $z$ directions) do not coincide with the peak wave frequency of the incoming waves $(0.658 \mathrm{~Hz})$. As a consequence, the inertial force due to the deck's dynamic response can be assumed to be minimal and insignificant in the load cell responses. 

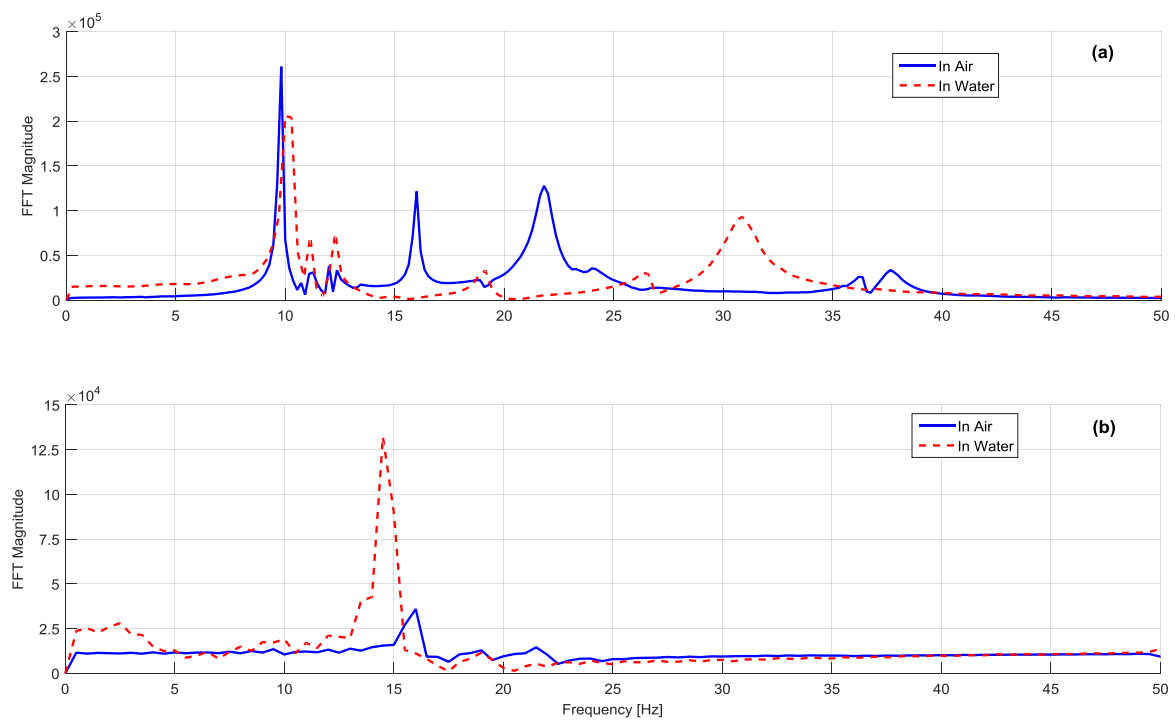

Figure 11. FFT results of free oscillation tests conducted in air and in water based on time traces of the load cells: (a) in $x$-direction; (b) in $z$-direction.

\section{Wave impact tests}

A total of 29 conditions were tested as summarised in Table 6. It is important to note that, in order to ensure the repeatability of the results each test condition was repeated $3-5$ times resulting in a total of 138 runs. Each run covered the measurements of force components (Horizontal and vertical) and localised pressures (impact and downward) such that approximately 2620 peaks were analysed and averaged to obtain reliable experimental data. As can be seen in Table 6, the dynamic air gap (denoted by a) was obtained for each condition using ( $a_{0}$ $\eta_{c}$ ). All test conditions, except 7, 14, 16, 24 and 26, show a negative air gap at the LE. Nevertheless, as discussed earlier the associated wave events (WE7 and WE9) caused wave impact nearby the TE for these conditions. 
Table 6. Test conditions.

\begin{tabular}{|c|c|c|c|c|}
\hline Condition & WE & $\eta_{\mathrm{c}}[\mathrm{mm}]$ & $\mathrm{a}_{0}[\mathrm{~mm}]$ & $\mathrm{a}[\mathrm{mm}]$ \\
\hline 1 & 1 & 153 & 120 & -33 \\
\hline 2 & 2 & 158 & 120 & -38 \\
\hline 3 & 3 & 129 & 120 & -29 \\
\hline 4 & 4 & 138 & 120 & -18 \\
\hline 5 & 5 & 163 & 120 & -43 \\
\hline 6 & 6 & 130 & 120 & -30 \\
\hline 7 & 7 & 112 & 120 & 8 \\
\hline 8 & 8 & 166 & 120 & -46 \\
\hline 9 & 1 & 153 & 110 & -33 \\
\hline 10 & 2 & 158 & 110 & -38 \\
\hline 11 & 4 & 138 & 110 & -18 \\
\hline 12 & 5 & 163 & 110 & -43 \\
\hline 13 & 6 & 130 & 110 & -30 \\
\hline 14 & 7 & 112 & 110 & 8 \\
\hline 15 & 8 & 166 & 110 & -46 \\
\hline 16 & 9 & 90 & 110 & 10 \\
\hline 17 & 10 & 118 & 110 & -8 \\
\hline 18 & 1 & 153 & 100 & -33 \\
\hline 19 & 2 & 158 & 100 & -38 \\
\hline 20 & 3 & 129 & 100 & 29 \\
\hline 21 & 4 & 138 & 100 & -18 \\
\hline 22 & 5 & 163 & 100 & -43 \\
\hline 23 & 6 & 130 & 100 & -30 \\
\hline 24 & 7 & 112 & 100 & 8 \\
\hline 25 & 8 & 166 & 100 & -46 \\
\hline 26 & 9 & 90 & 100 & 10 \\
\hline 27 & 10 & 118 & 100 & -8 \\
\hline 28 & 11 & 112 & 100 & -12 \\
\hline 29 & 12 & 104 & 100 & -4 \\
\hline
\end{tabular}

\section{Results and discussion}

Wave-in-deck forces in the $x$-direction $\left(\mathrm{F}_{\mathrm{x}}\right)$ and $z$-direction $\left(\mathrm{F}_{\mathrm{z}}\right)$ as well as localised pressures associated with 
the test conditions shown in Table 6 are presented and discussed in this section. WE1 $(\mathrm{H}=253 \mathrm{~mm})$ and WE8 $(\mathrm{H}=249 \mathrm{~mm})$, which are considered the most extreme amongst the investigated wave events, have been selected for detailed discussion in terms of repeatability analyses.

\section{Wave-in-deck forces}

To assess the uncertainty in the experimental data each test condition was repeated between 3 and 5 times. The peak values in the $x$ - and $z$-direction measured in the multiple runs were then averaged to obtain a mean value. The force peaks in the $z_{-}$-direction were found for both the upward direction, $F_{z}(\uparrow)$, and the downward direction, $\mathrm{F}_{z}(\downarrow)$.

The maximum values of the three force components $\left(F_{x}, F_{z}(\uparrow)\right.$ and $\left.F_{z}(\downarrow)\right)$ measured for WE1 are summarised in Table 7 for test conditions 1, 9 and 18 (see Table 6). For all the tabulated conditions, good repeatability can be seen for $F_{x}$ and $F_{z}(\uparrow)$. However significant variability was found in the values of $F_{z}(\downarrow)$, e.g. in condition 1 a relative difference of approximately 12\% was obtained between Run 1 and Run 2 .

Table 7. Wave event 1 (WE1) force peaks [given in Newton] measured using multiple runs for conditions 1, 9 and 18.

\begin{tabular}{|c|c|c|c|c|c|c|c|}
\hline \multicolumn{7}{|c|}{ Condition 1: $\eta_{\mathrm{c}}=153 \mathrm{~mm}, \mathrm{~T}_{\mathrm{z}}=1.37 \mathrm{~s}, \mathrm{a}_{0}=120 \mathrm{~mm}$} \\
\hline Component & Run 1 & Run 2 & Run 3 & Run 4 & Run 5 & Mean & Std. Dev. $(\sigma)$ \\
\hline $\mathrm{F}_{\mathrm{x}}$ & 12.7 & 11.9 & 12.4 & 11.7 & 12 & 12.1 & 0.40 \\
\hline $\mathrm{F}_{\mathrm{z}}(\uparrow)$ & 29.1 & 28.8 & 27.7 & 28.6 & 28.8 & 28.6 & 0.53 \\
\hline $\mathrm{F}_{\mathrm{z}}(\downarrow)$ & -62.3 & -70.5 & -70.3 & -70.4 & -63.7 & -67.4 & 4.08 \\
\hline \multicolumn{7}{|c|}{ Condition 9: $\eta_{\mathrm{c}}=153 \mathrm{~mm}, \mathrm{~T}_{\mathrm{z}}=1.37 \mathrm{~s}, \mathrm{a}_{0}=110 \mathrm{~mm}$} \\
\hline Component & Run 1 & Run 2 & Run 3 & Run 4 & Run 5 & Mean & Std. Dev. $(\sigma)$ \\
\hline $\mathrm{F}_{\mathrm{x}}$ & 15.7 & 15.8 & 14.7 & 15.5 & 15.9 & 15.5 & 0.48 \\
\hline $\mathrm{F}_{\mathrm{z}}(\uparrow)$ & 38.8 & 38.2 & 37.8 & 39.1 & 39.3 & 38.6 & 0.63 \\
\hline $\mathrm{F}_{\mathrm{z}}(\downarrow)$ & -98.7 & -80.2 & -85.7 & -97 & -88.3 & -90 & 7.78 \\
\hline \multicolumn{7}{|c|}{ Condition 18: $\eta_{\mathrm{c}}=153 \mathrm{~mm}, \mathrm{~T}_{\mathrm{z}}=1.37 \mathrm{~s}, \mathrm{a}_{0}=100 \mathrm{~mm}$} & \\
\hline Component & Run 1 & Run 2 & Run 3 & Run 4 & Run 5 & Mean & Std. Dev. $(\sigma)$ \\
\hline $\mathrm{F}_{\mathrm{x}}$ & 24.6 & 24.7 & 24.2 & 24.6 & 25.1 & 24.6 & 0.32 \\
\hline $\mathrm{F}_{\mathrm{z}}(\uparrow)$ & 57.9 & 56.9 & 57.6 & 55.8 & 56 & 56.8 & 0.93 \\
\hline $\mathrm{F}_{\mathrm{z}}(\downarrow)$ & -181 & -104 & -77.5 & -103 & -82.8 & -109.7 & 41.60 \\
\hline
\end{tabular}

By analysing the time history associated with WE8 for test conditions 8, 15 and 25, the force peaks are obtained 
as given in Table 8. A good repeatability was also obtained amongst repeated runs in the three conditions. Hence, there is a sufficient confidence in the mean values reported in this paper. Nevertheless, a close view was done in regards to the dynamic response of the impacted deck structure and its effect on the wave-in-deck forces.

Table 8. Wave event 8 (WE8) force peaks [given in Newton] measured using multiple runs for conditions 8, 15 and 25.

\begin{tabular}{|c|c|c|c|c|c|c|c|}
\hline \multicolumn{8}{|c|}{ Condition 8: $\eta_{\mathrm{c}}=166 \mathrm{~mm}, \mathrm{~T}_{\mathrm{z}}=1.49 \mathrm{~s}, \mathrm{a}_{0}=120 \mathrm{~mm}$} \\
\hline Component & Run 1 & Run 2 & Run 3 & Run 4 & Run 5 & Mean & Std. Dev. $(\sigma)$ \\
\hline $\mathrm{F}_{\mathrm{x}}$ & 63.1 & 63.2 & 55.4 & 53.2 & 51.2 & 57.2 & 5.61 \\
\hline $\mathrm{F}_{\mathrm{z}}(\uparrow)$ & 33.2 & 31.9 & 28.6 & 29.8 & 28.5 & 30.4 & 2.08 \\
\hline $\mathrm{F}_{\mathrm{z}}(\downarrow)$ & -57.4 & -58.9 & -53.9 & -57.7 & -54.3 & -56.4 & 2.21 \\
\hline \multicolumn{8}{|c|}{ Condition 15: $\eta_{\mathrm{c}}=166 \mathrm{~mm}, \mathrm{~T}_{\mathrm{z}}=1.49 \mathrm{~s}, \mathrm{a}_{0}=110 \mathrm{~mm}$} \\
\hline Component & Run 1 & Run 2 & Run 3 & Run 4 & Run 5 & Mean & Std. Dev. $(\sigma)$ \\
\hline $\mathrm{F}_{\mathrm{x}}$ & 55.2 & 66.2 & 57.9 & 69.3 & 60.7 & 61.9 & 5.82 \\
\hline $\mathrm{F}_{\mathrm{z}}(\uparrow)$ & 53.3 & 52.4 & 50.1 & 53.7 & 53.7 & 52.6 & 1.52 \\
\hline $\mathrm{F}_{\mathrm{z}}(\downarrow)$ & -64.4 & -70.1 & -67 & -69.8 & -66.1 & -67.5 & 2.44 \\
\hline \multicolumn{8}{|c|}{ Condition $25: \eta_{\mathrm{c}}=166 \mathrm{~mm}, \mathrm{~T}_{\mathrm{z}}=1.49 \mathrm{~s}, \mathrm{a}_{0}=100 \mathrm{~mm}$} \\
\hline Component & Run 1 & Run 2 & Run 3 & Run 4 & Run 5 & Mean & Std. Dev. $(\sigma)$ \\
\hline $\mathrm{F}_{\mathrm{x}}$ & 80.9 & 67 & 77.1 & 78.4 & 71.9 & 75.1 & 5.22 \\
\hline $\mathrm{F}_{\mathrm{z}}(\uparrow)$ & 70.5 & 63.1 & 67.9 & 69.8 & 69.7 & 68.2 & 3.14 \\
\hline $\mathrm{F}_{\mathrm{z}}(\downarrow)$ & -66.3 & -64.2 & -67.5 & -62.6 & -66.1 & -65.3 & 2.15 \\
\hline
\end{tabular}

\section{Force time history}

In order to investigate the force variation, time histories of the force measurements are presented for multiple runs. For condition 1, the horizontal and vertical wave-in-deck forces measured over each of the five runs for WE1 and an air gap of $120 \mathrm{~mm}$ are shown in Figure 12 and Figure 13, respectively, with the time vectors manually synchronised. Both time histories show an impulse-like impact i.e. force magnitude sharply increased and then followed by a rapid decrease. It is clear that the dynamic response is more pronounced in the horizontal direction than in the vertical direction (Time $=16.25-17.5 \mathrm{~s}$ ). This can be attributed to a combination of the direction of travel of the wave and the free horizontal motion at the slider attachment of LC2 of the deck model. However, this dynamic effect appears only after the main deck impact at approximately 
$16.1 \mathrm{~s}$.

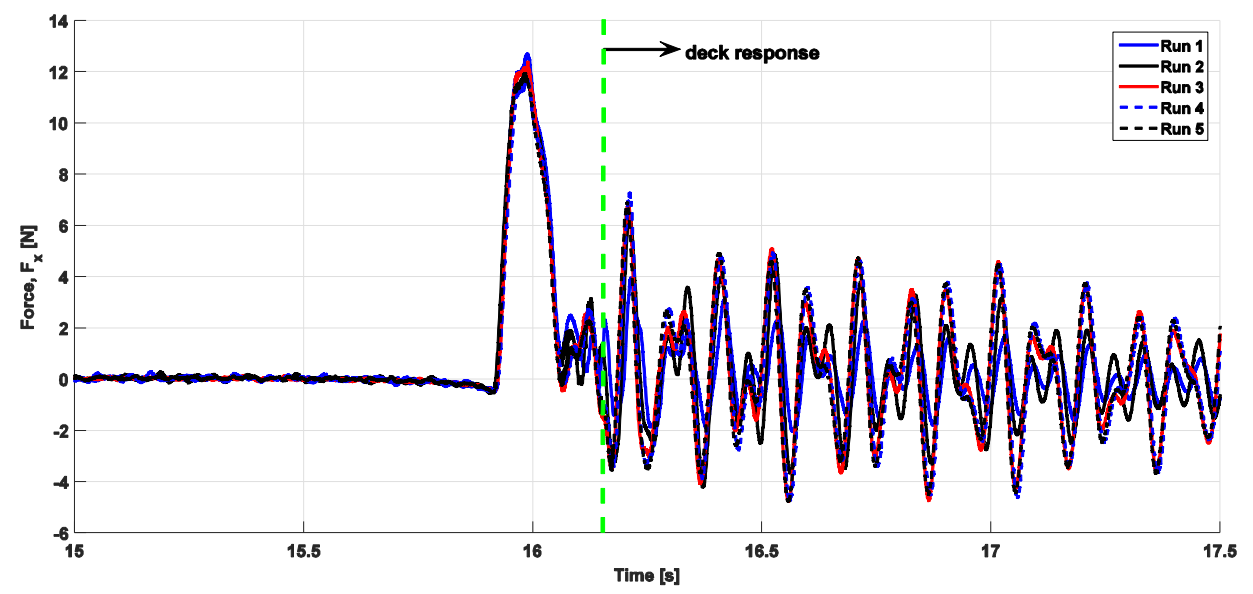

Figure 12. Time history of the horizontal force $\left(F_{x}\right)$ for condition 1 [WE 1 at $\mathrm{a}_{0}=120 \mathrm{~mm}$ ].

The ratio between the maxima of the horizontal and vertical upwards forces was found to be approximately 0.41. The vertical force signal, illustrated in Figure 13, has a large downwards component - approximately double the upwards component. Analysis of the video records of this event, as shown in Figure 14, suggests that the large magnitude of the downwards force is related to the added mass surrounding the immersed deck structure, in both $x$ and $z$ directions. The figure clearly shows a substantial amount of downwards flowing water from the LE of the deck after the wave impact. 


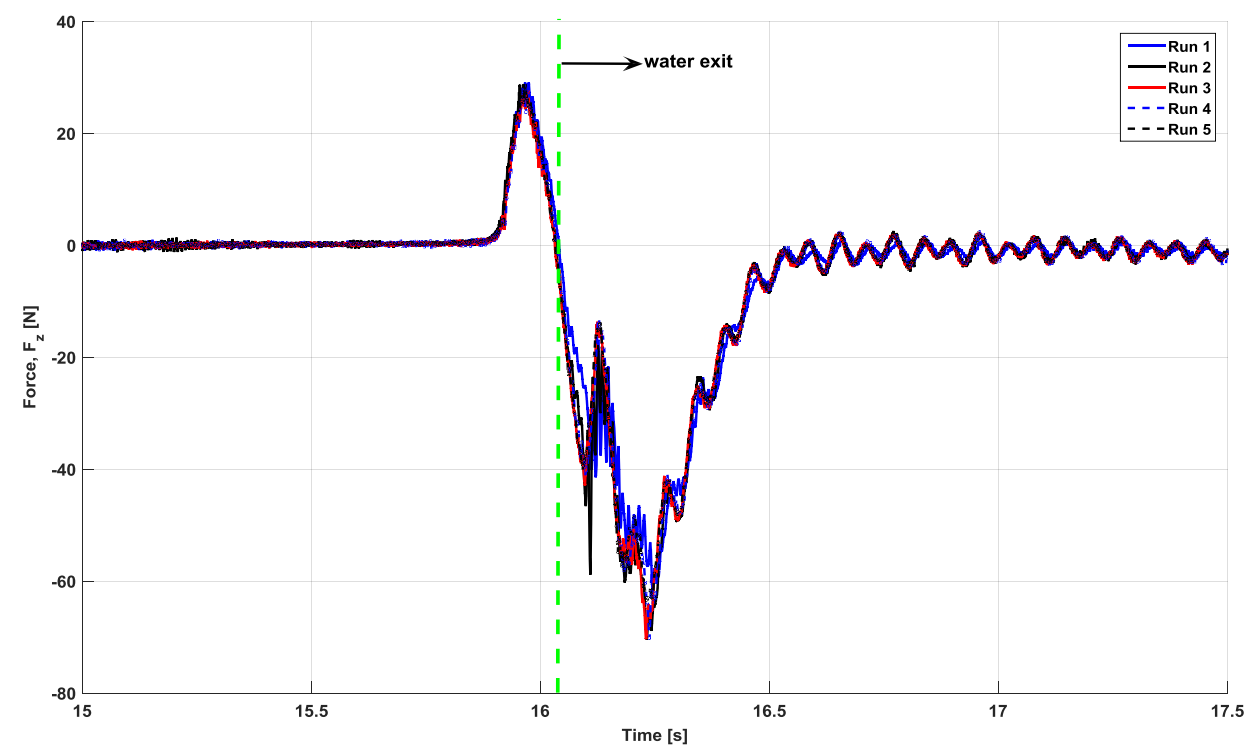

Figure 13. Time history of the vertical force $\left(F_{z}\right)$ for condition 1 [WE 1 at a $a_{0}=120 \mathrm{~mm}$ ].

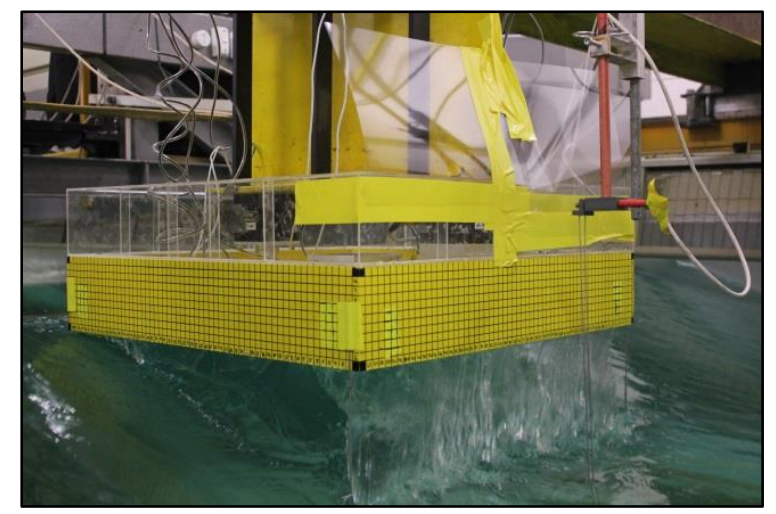

Figure 14. Photograph showing substantial amount of downwards flowing water from the LE of the deck after the wave impact. WE 1 at $\mathrm{a}_{0}=120 \mathrm{~mm}$.

Since the front face of the deck structure acts as a vertical wall against which the waves impact, the impacts can take a form akin to a breaking wave or jet-like impact. Subsequent to this impact a large amount of water will contribute into the magnitude of the downward $\mathrm{F}_{\mathrm{z}}$ component (see Figure 14, water flowing down at the LE immediately after hitting the front face). In other words, the bottom plate of a box-type deck structure is impacted in a manner similar to a horizontal flat plate, except that the amount of water passing the plate (which 
causes the vertical wave-in-deck force $F_{z}$ ) is controlled by the magnitude of the horizontal force. This finding is in contrast with the theoretical models which assume that the deck structure is transparent to the impacting waves ${ }^{31}$.

\section{Identification of dynamic response}

Impacting waves contain high-frequency energy components that cause the structure to respond at its modal frequencies $14,17,32,33$. This impact-induced vibration can corrupt the real force measurements since the load cells records include the inertial force. Consequently, prior to determining the actual peaks of force data, the inertial force should be identified and removed from the measured signal. Whilst Windsor ${ }^{17}$ describes various techniques suitable for removing the inertial force from measured force signals, the simplest method is using low-pass filtering. The characteristics (e.g. cut-off frequency) of the low-pass filter are often selected based on dry and wet free oscillation tests $14,34,35$. However, free oscillation tests do not accurately represent the actual wave-structure interaction and thus the signal information may be misinterpreted or lost when filtering. An alternative is to use FFT to analyse the force signal in the frequency domain to remove high frequency components that can be idealised as a single degree of freedom system. Nevertheless, an analysis of the spectral density of the impact generally contains frequencies attributed to multiple degrees of freedom. Therefore, as concluded by Winsor ${ }^{17}$, neither of these techniques produce fully satisfactory results for the removal of the inertial force from the force signal.

Oberlies, Khalifa ${ }^{33}$ used a calibrated impulse hammer to compare the input force with the force response measured by the load cells on a model of a gravity-based structure. Oberlies, Khalifa ${ }^{33}$ found that the dynamics of the test rig during a hydrodynamic impact differed significantly from those obtained with the hammer test; this leads to questioning of the validity of using an impulse hammer to identify the inertial force.

In this work, in order to identify and remove the inertial forces (generally speaking, "remove the effect of the inertial forces") from the measured force data, the following procedure is proposed:

- First dry and wet free oscillation tests are performed as discussed previously to obtain the natural frequency of the testing assembly (deck model, instruments and force supports). 
- The next step is to investigate the magnitude of the inertial force during wave-in-deck impact events by recording the translational acceleration components in both the $x$ - and $z$-direction using an accelerometer.

- The inertial force in the $x$ - and $z$-direction can then be identified from the accelerometer signal in the time domain and its magnitude estimated using Newtown's second law as m.ax and m.az, respectively, where $\mathrm{m}$ is the structural mass of the deck model including support members $(\approx 17.75 \mathrm{~kg})$ and $\mathrm{a}_{\mathrm{x}}$ and $a_{z}$ are the horizontal and vertical peak accelerations measured during each wave impact event. The water added mass in both directions is neglected.

- Finally, the actual measured peaks of horizontal force $F_{x}$ and vertical force $F_{z}$ are obtained by subtracting the estimated inertial forces $\left(\mathrm{F}_{\mathrm{ix}}\right.$ and $\left.\mathrm{F}_{\mathrm{iz}}\right)$ due to the dynamic deck response from raw force values.

The original load cell signals and the estimated inertial forces, $\mathrm{F}_{\mathrm{ix}}$ and $\mathrm{F}_{\mathrm{iz}}$ in the $x$ - and $z$-direction, are presented in Figure 15 (a) and (b), respectively for condition 1 using Run 4. It shows no dynamic response at the instant of wave impact (time $\approx 15.9$ s); however the deck's dynamic response becomes visible at the water exit phase of WE1 and thereafter (time $=16.1 \mathrm{~s}$ ). This can be attributed as the applied force i.e. water impact has an ideal instantaneous load step and therefore the system which was at rest will respond after a time delay. This suggests that the deck structure will start vibrating shortly after the wave slam event (which often elapses a very short duration). Therefore the dynamic response will have a minimal effect on the peak forces in $F_{x}$ and the upward $\mathrm{F}_{z}$. Beyond the water exit phase the deck structure seems to continuously vibrate with a settling time exceeding 2.0 s. Such a long duration may not be tolerated for wave impact experiments, particularly when two successive large waves hit the model thereby the force time history of the second impact may be corrupted.

For the procedure of estimation the inertial forces, it can be appreciated that the magnitude of inertial forces is well estimated, as a result of product the structural mass in the magnitude of $a_{x}$ and $a_{z}$, in comparison with the load cell responses (Figure 15). This implies that the load cells have detected the dynamic response of the deck structure and introduced as an additional impact force. Since a minimal effect of the dynamic response of the 
deck structure on the peak force values (although it had effect on the force time history), peak values of force components are extracted from the raw data and discussed hereafter.
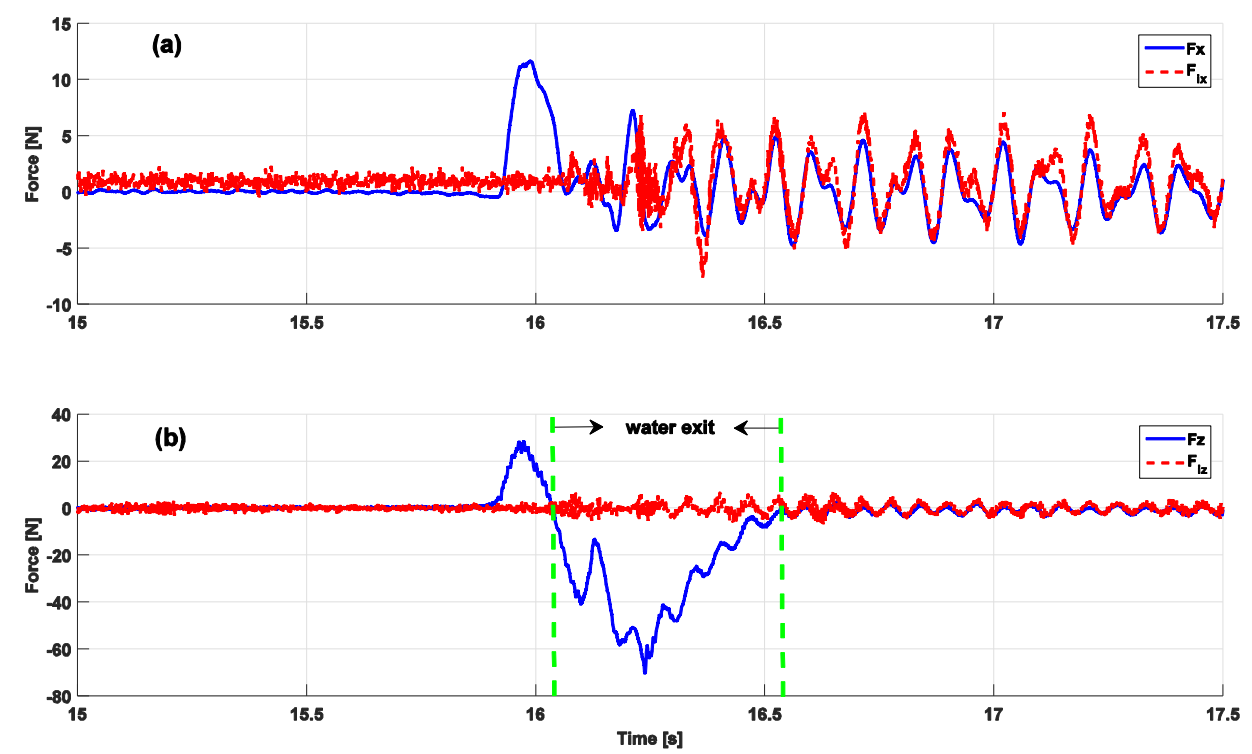

Figure 15. Time history of original (raw) forces and estimated inertial forces $\left(\mathrm{F}_{\mathrm{ix}}\right.$ and $\mathrm{F}_{\mathrm{iz}}$ ) associated with Run 4: (a) $x$ direction; (b) z-direction.

\section{Deck clearance effect}

The effect of deck clearance on the measured forces is discussed in this section. Table 9 shows the change in the horizontal force $\left(F_{\mathrm{x}}\right)$ for different deck clearances due to 12 wave events. Peak forces from different runs were averaged and listed against each wave event. A correlation between $\mathrm{u}$ and $\mathrm{F}_{\mathrm{x}}$ peaks is evident such that the WE5 $\left(\eta_{\mathrm{c}}=163 \mathrm{~mm}, \mathrm{u}=0.95 \mathrm{~m} / \mathrm{s}\right)$ produced the largest horizontal forces. In terms of wave severity, four wave conditions out of 12 including WE1, 2, 5 and 8 were found to be the most severe events. Hence, they were chosen for further discussion when analysing the vertical force and localised pressures.

Table 9. A summary of the averaged peak values of the horizontal force $\left(\mathrm{F}_{\mathrm{x}}\right)$.

\begin{tabular}{|c|c|c|c|c|c|c|c|}
\hline \multirow{2}{*}{ WE } & \multirow{2}{*}{$\eta_{\mathrm{c}}[\mathrm{mm}]$} & $\mathrm{u}[\mathrm{m} / \mathrm{s}]$ & $\mathrm{S}[-]$ & \multirow{2}{*}{$\beta[-]$} & \multicolumn{3}{|c|}{ Force, $\mathrm{F}_{\mathrm{x}}[\mathrm{N}]$} \\
\cline { 5 - 8 } & & & & & $\mathrm{a}_{0}=120 \mathrm{~mm}$ & $\mathrm{a}_{0}=110 \mathrm{~mm}$ & $\mathrm{a}_{0}=100 \mathrm{~mm}$ \\
\hline 1 & 153 & 0.803 & 0.086 & 0.61 & 12.1 & 15.5 & 24.6 \\
\hline
\end{tabular}




\begin{tabular}{|c|c|c|c|c|c|c|c|}
2 & 158 & 0.92 & 0.098 & 0.583 & 16.1 & 21.4 & 29.8 \\
\hline 3 & 129 & 0.56 & 0.06 & 0.606 & 1.2 & - & 7.7 \\
\hline 4 & 138 & 0.42 & 0.041 & 0.726 & 5.6 & 9.8 & 15.6 \\
\hline 5 & 163 & 0.95 & 0.103 & 0.674 & 88.2 & 96.7 & - \\
\hline 6 & 130 & 0.71 & 0.083 & 0.657 & 1.2 & 4.31 & 7.7 \\
\hline 7 & 112 & 0.66 & 0.082 & 0.609 & 0.9 & 3.7 & 6.2 \\
\hline 8 & 166 & 0.72 & 0.072 & 0.667 & 57.2 & 61.9 & 75.1 \\
\hline 9 & 90 & 0.29 & 0.028 & 0.573 & - & 2.8 & 3.9 \\
\hline 10 & 118 & 0.61 & 0.075 & 0.702 & - & 4.1 & 9.9 \\
\hline 11 & 112 & 0.78 & 0.1 & 0.589 & - & - & 14.3 \\
\hline 12 & 104 & 0.32 & 0.032 & 0.675 & - & - & 9.8 \\
\hline
\end{tabular}

The averaged horizontal force peaks were normalised by $0.5 \rho \mathrm{Au}^{2}$, in which $\mathrm{A}$ is the impact area in $x$-direction estimated by $A=B\left(\eta_{c}-a_{0}\right)$. Figure 16 shows the normalised peak values $\left(F^{*}\right)$ versus wave skewness, $\beta$ at the three deck clearances tested. The ratio of 2.5 is a force coefficient recommended by the certification bodies for end - on and broadside wave directions $2,29,36$. As it can be observed that in many cases the force ratio was found to exceed the recommended value (2.5), particularly with increasing wave skewness. 

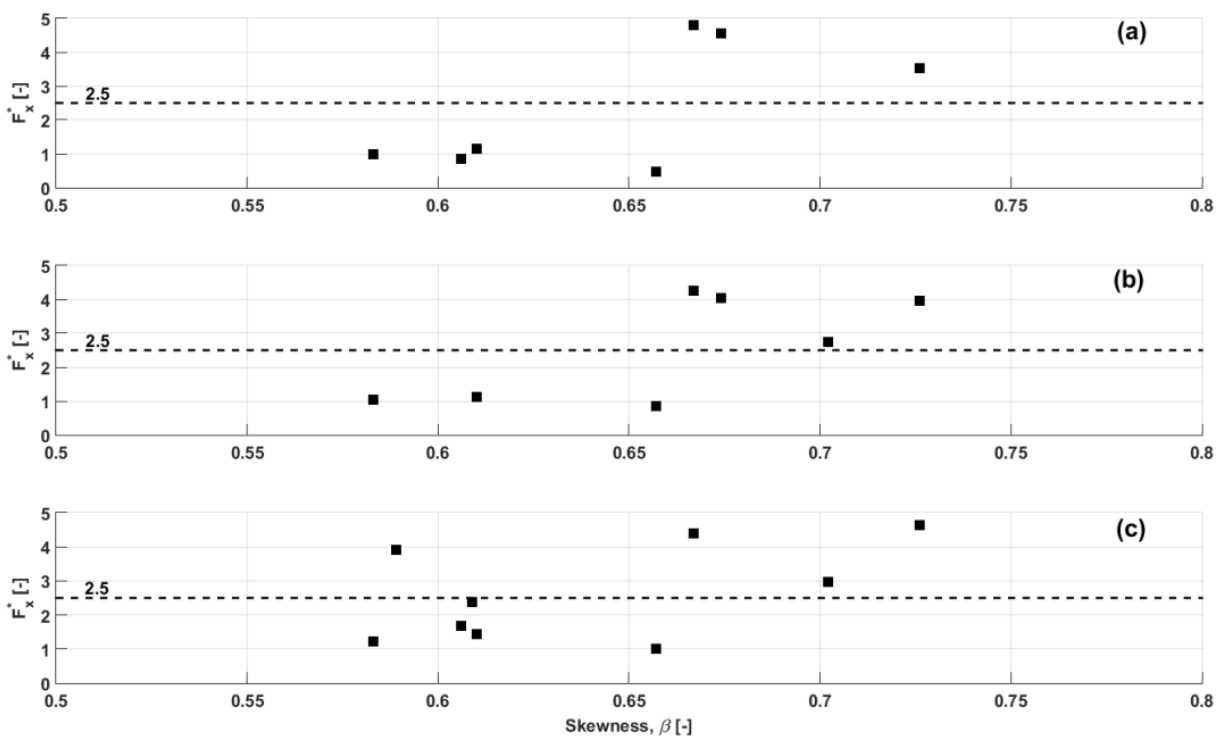

Figure 16. Normalised horizontal peak forces $\left[\mathrm{F}^{*}{ }_{\mathrm{x}}=0.5 \rho \mathrm{Au}^{2}\right]$ versus wave skewness $(\beta)$ : (a) $\mathrm{a}_{0}=120 \mathrm{~mm}$; (b) $\mathrm{a}_{0}=110$ $\mathrm{mm} ;$ (c) $\mathrm{a}_{0}=100 \mathrm{~mm}$.

In order to examine the effect of deck clearance reduction on the measured force peak values in $x$-direction, the peak values obtained at $\mathrm{a}_{0}=110 \mathrm{~mm}$ and $\mathrm{a}_{0}=100 \mathrm{~mm}$ were divided by those measured at the original deck clearance $\left(\mathrm{a}_{0}=120 \mathrm{~mm}\right)$. As shown in Table 10 , a $10-\mathrm{mm}$ reduction was found to amplify the force peaks by $28 \%$ in WE1 and 33\% in WE2. The deck structure experienced much larger forces at $\mathrm{a}_{0}=100 \mathrm{~mm}$ in comparison with $\mathrm{a}_{0}=120$ (20-mm reduction), for instance, the peak values in WE1 and WE2 increased by factors of approximately $2.03(103 \%)$ and $1.85(85 \%)$.

Table 10. The effect of deck clearance reduction on the peak values of the horizontal force $\left(\mathrm{F}_{\mathrm{x}}\right)$.

\begin{tabular}{|c|c|c|c|c|}
\hline WE & $\eta_{c}[\mathrm{~mm}]$ & $\mathrm{T}_{z}[\mathrm{~s}]$ & $\begin{array}{c}10-\mathrm{mm} \text { Reduction } \\
{[-]}\end{array}$ & $\begin{array}{c}20-\text { mm Reduction } \\
{[-]}\end{array}$ \\
\hline 1 & 153 & 1.37 & 1.28 & 2.03 \\
\hline 2 & 158 & 1.33 & 1.33 & 1.85 \\
\hline 5 & 163 & 1.23 & 1.10 & - \\
\hline 8 & 166 & 1.49 & 1.08 & 1.31 \\
\hline
\end{tabular}


Likewise, Table 11 shows the effect of deck clearance on the peak values of the vertical upward force component, $F_{z}(\uparrow)$, due to the most severe wave events observed in this investigation. One can appreciate that $\mathrm{F}_{\mathrm{z}}(\uparrow)$ peak values were significantly amplified as a result of reducing the deck clearance. For example, a $20-\mathrm{mm}$ reduction $\left(2.5 \mathrm{~m}\right.$ full scale) caused amplification ratios in $\mathrm{F}_{\mathrm{z}}(\uparrow)$ peak values to approximately $2.0(100 \%)$ in WE1, $1.88(88 \%)$ in WE2, $1.95(95 \%)$ in WE5 and $2.24(124 \%)$ in WE8.

Table 11. The effect of deck clearance reduction on the peak values of the upward vertical force, $F_{z}(\uparrow)$.

\begin{tabular}{|c|c|c|c|c|c|c|c|}
\hline \multirow{2}{*}{ WE } & \multirow{2}{*}{$\eta_{\mathrm{c}}[\mathrm{mm}]$} & \multirow{2}{*}{$\mathrm{S}[-]$} & \multicolumn{3}{|c|}{ Force, $\mathrm{F}_{\mathrm{z}}[\mathrm{N}]$} & \multirow{2}{*}{$\begin{array}{c}\text { 10-mm Reduction } \\
{[-]}\end{array}$} & \multirow{2}{*}{$\begin{array}{c}\text { 20-mm Reduction } \\
{[-]}\end{array}$} \\
\hline & & & $\mathrm{a}_{0}=120 \mathrm{~mm}$ & $\mathrm{a}_{0}=110 \mathrm{~mm}$ & $\mathrm{a}_{0}=100 \mathrm{~mm}$ & & \\
\hline 1 & 153 & 0.086 & 28.6 & 38.6 & 56.8 & 1.35 & 1.99 \\
\hline 2 & 158 & 0.098 & 31.3 & 42 & 58.8 & 1.34 & 1.88 \\
\hline 5 & 163 & 0.103 & 40.5 & 50 & 79 & 1.23 & 1.95 \\
\hline 8 & 166 & 0.072 & 30.4 & 52.6 & 68.2 & 1.73 & 2.24 \\
\hline
\end{tabular}

The averaged vertical force peaks were normalised by the maximum instantaneous buoyancy force associated with each wave event $\rho \mathrm{gLB}\left(\eta_{\mathrm{c}}-\mathrm{a}_{0}\right)$ in which $\mathrm{L}$ and $\mathrm{B}$ is the deck length/breadth $(0.608 \mathrm{~m})$ and $\mathrm{g}$ is acceleration due to gravity. The term $\rho \mathrm{gLB}\left(\eta_{\mathrm{c}}-\mathrm{a}_{0}\right)$ was obtained by assuming that the deck is fully submerged in $x$-direction during wave impact i.e. wetted length is equal the deck length $(L)$. On average the $F_{z}(\uparrow)$ peak values were found to be a quarter (0.25) of the maximum buoyancy force associated with the wave impact, see Figure 17. 


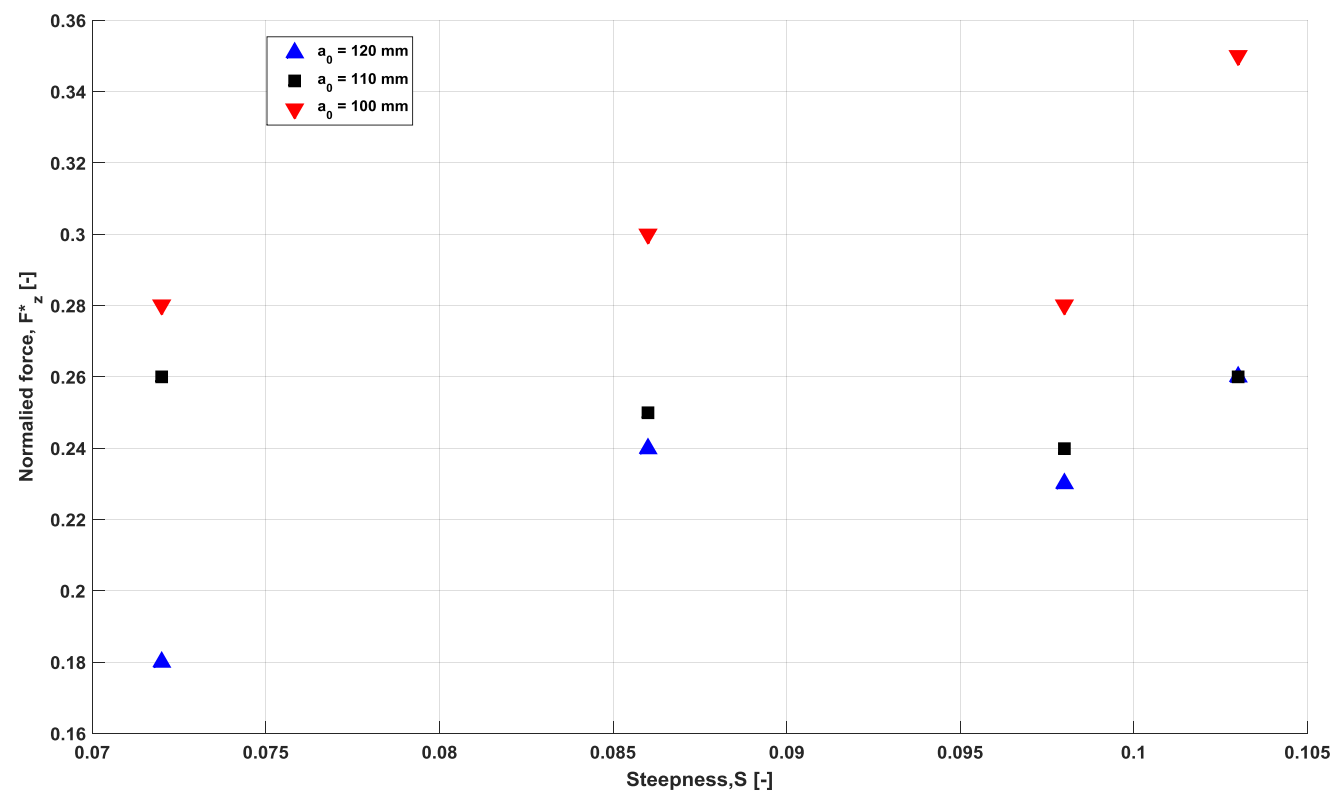

Figure 17. Normalised upward vertical peak forces $\left[\mathrm{F}^{*}{ }_{\mathrm{z}}=\rho \mathrm{gLB}\left(\eta_{\mathrm{c}}-\mathrm{a}_{0}\right)\right]$ versus wave steepness, $\mathrm{S}$, at different $\mathrm{a}_{0}$.

\section{Localised impact wave pressures}

Pressure time history

As an example, Figure 18 shows the time history of PT\#1 in runs 1 and 2 for test condition 1 (WE1, a 0120 $\mathrm{mm})$. As can be noted the time history in both runs has a similar trend in the uplift direction i.e. positive cycle. Nevertheless, the first peak in Run 1 is significantly larger than the one measured in Run 2. It can also be observed that in both runs, the duration of the positive pressures was found to be approximately $100 \mathrm{~ms}$ or $7 \% \mathrm{~T}_{z}$ (dots (1) and (2) are to denote the cycle end). The ratio between the maximum positive pressures (impact pressure, $\mathrm{P}_{\mathrm{i}}$ ) in both runs was found to be 0.92 (almost an $8 \%$ difference). However, using the area under each curve (impulse pressure), as suggested by Cooker ${ }^{37}$, the ratio was reduced to 1.01 or only a $1 \%$ difference. 


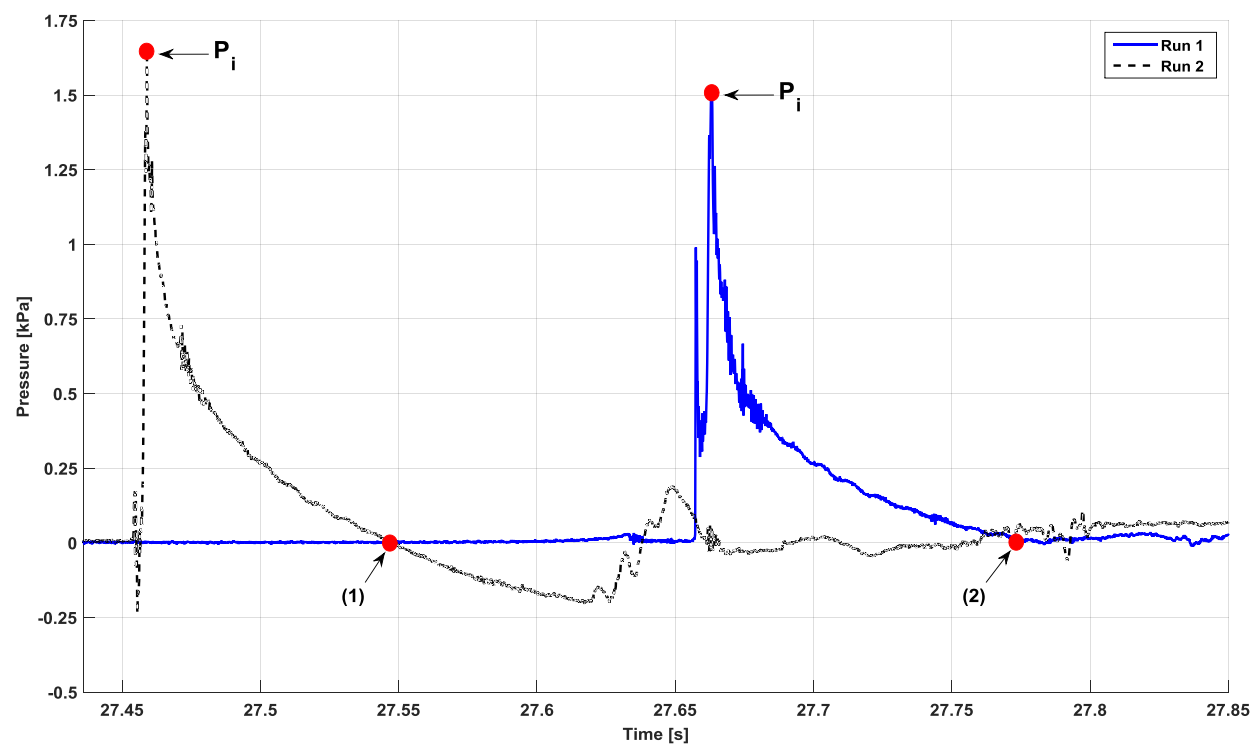

Figure 18. A typical time history of pressure signal measured by PT\#1 in different runs for condition 1 [WE1, $\mathrm{a}_{0}=120$ $\mathrm{mm}$.

\section{Pressure repeatability}

Repeatability of pressure measurements is introduced in this section by demonstrating the impact pressures associated with WE1 measured in multiple runs. The test conditions 1, 9 and 18 presented above in Table 7 are discussed herein in terms of localised impact pressures. The pressure distribution along the bottom plate is presented using boxplots such that the variation among the different runs can be investigated.

The associated impact pressures i.e. peak positive pressure with conditions 1, 9 and 18 measured over repeated

runs

can

be

shown

in

Figure

19, 


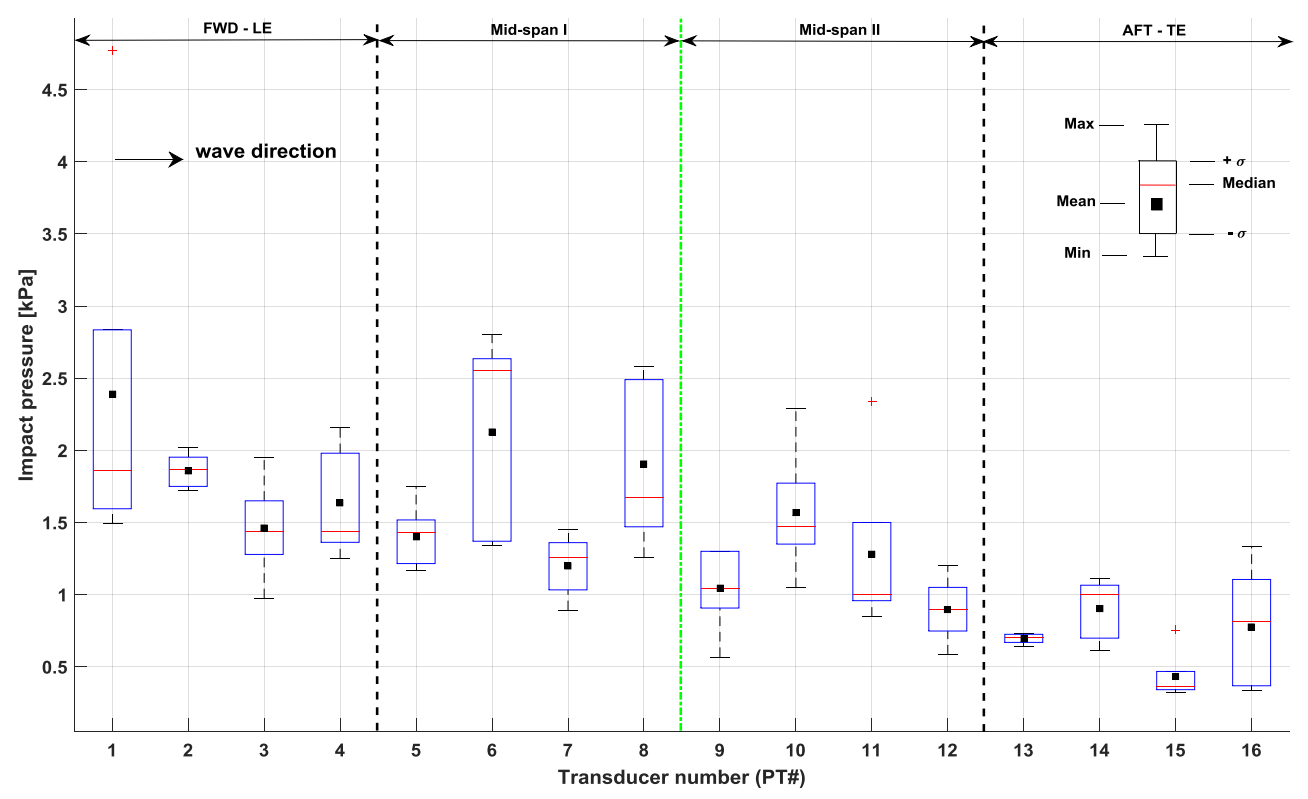

Figure 19. Impact pressures measured by sixteen PTs in multiple runs for condition 1 [WE1 at a $0=120 \mathrm{~mm}$ ]. and 


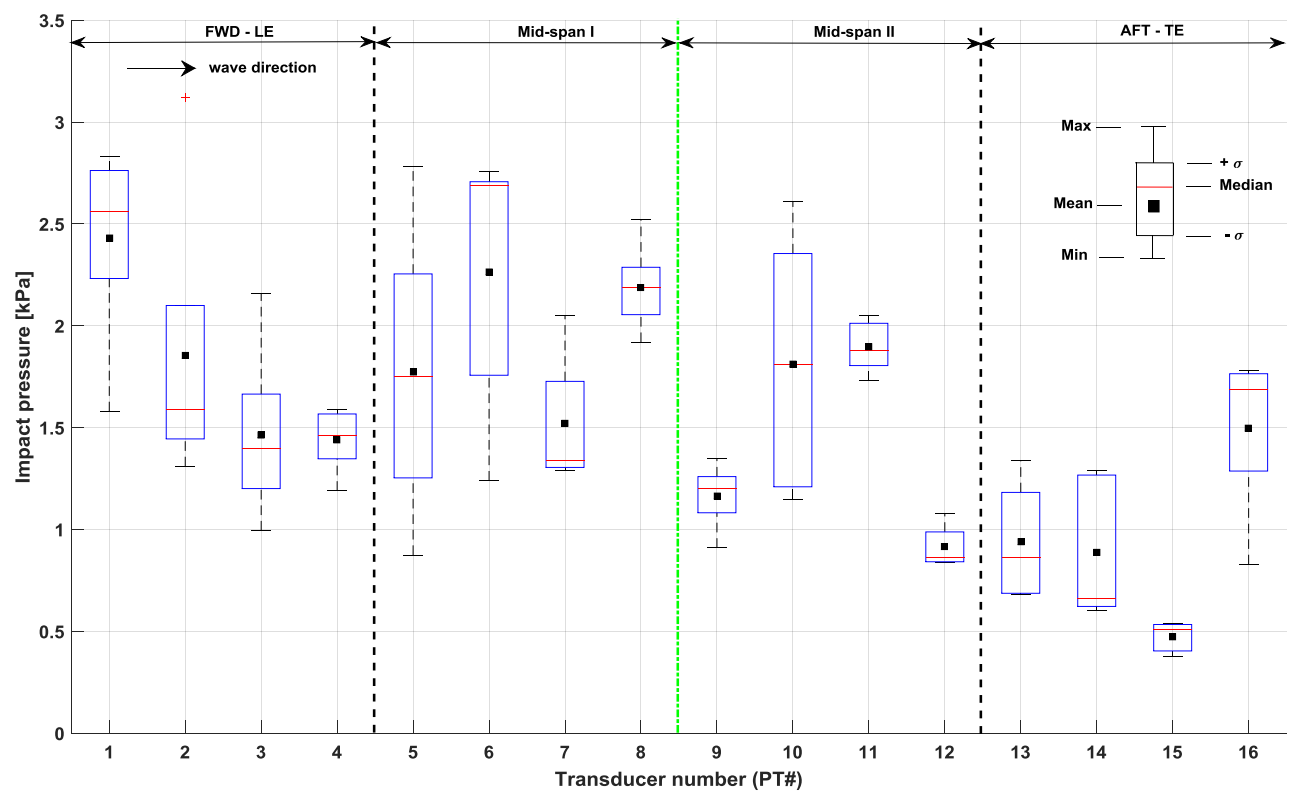

Figure 20. Impact pressures measured by sixteen PTs in multiple runs for condition 9 [WE1 at a0 $=110 \mathrm{~mm}$ ].

, respectively. The vertical centreline between PT\#8 and PT\#9 denotes the geometric centroid $(x=0)$ of the bottom plate. The boxplot definition is given in the legend of each graph. The square symbol (•) represents the mean value of peak pressures measured by a transducer in different runs.

In all three conditions, it can be seen that the front half of the bottom plate, FWD-LE and Mid-span I (PT\#1 - PT\#8), experienced higher pressures than the rear section. For condition 1 (Figure 19), the maximum peak pressure was captured by PT\#1 with a mean value of approximately $2.38 \mathrm{kPa}$. It is worth mentioning that, for this condition, only PT\#1, PT\#11 and PT\#15 are expected to detect outliers as depicted by cross marks $(+)$. For

condition

9 


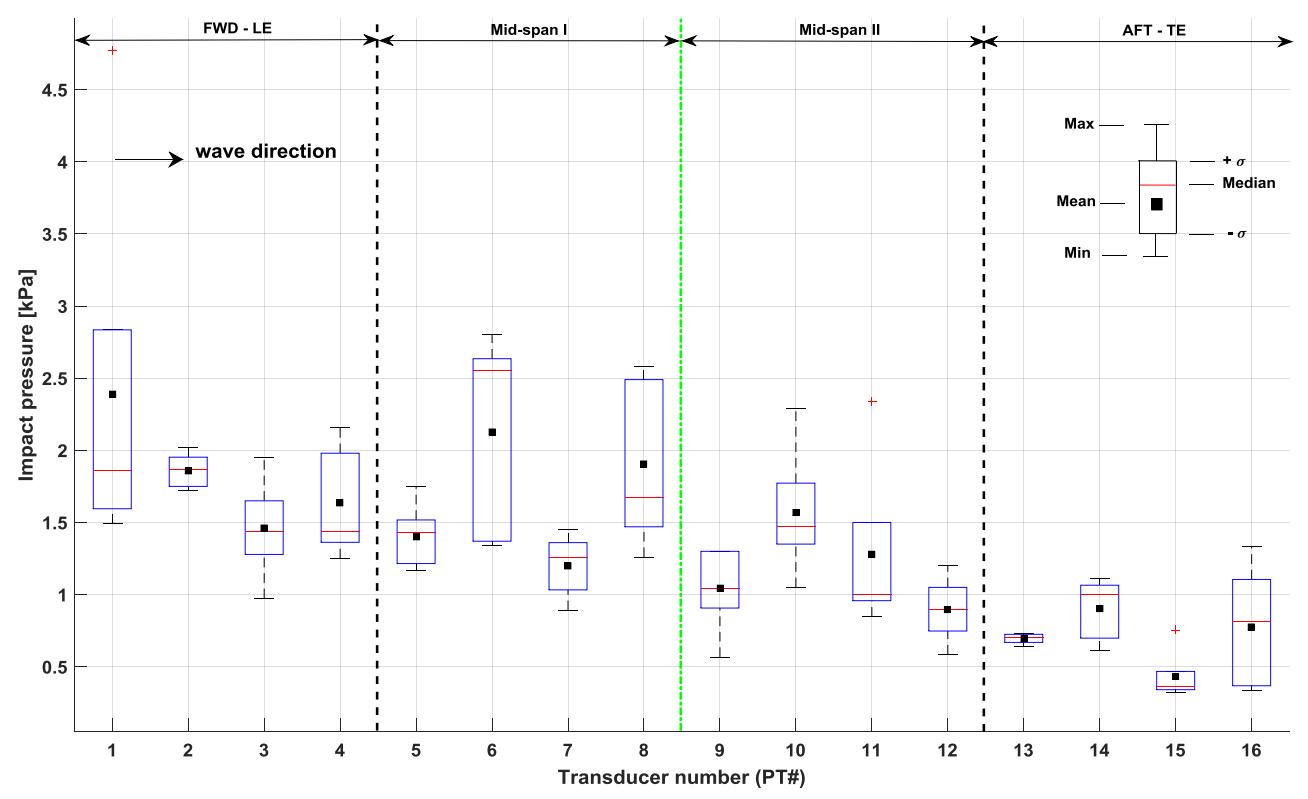

Figure 19. Impact pressures measured by sixteen PTs in multiple runs for condition 1 [WE1 at a $0=120 \mathrm{~mm}$ ].

), the maximum peak pressure was also captured by PT\#1 with a mean value of approximately $2.48 \mathrm{kPa}$, whilst for

condition

18 


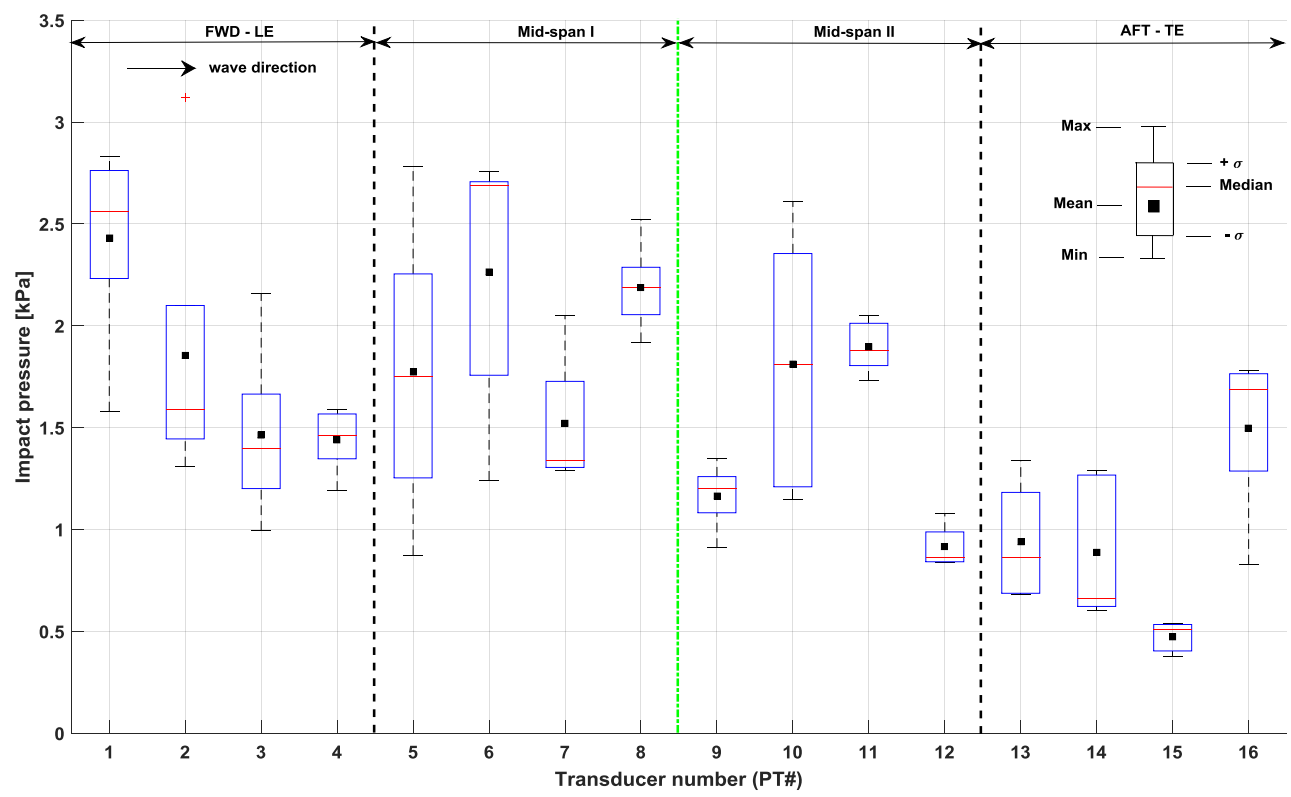

Figure 20. Impact pressures measured by sixteen PTs in multiple runs for condition 9 [WE1 at a0 $=110 \mathrm{~mm}$ ].

), the maximum peak pressure was captured by PT\#8 (2.6 kPa) and PT\#11 (2.7 kPa). Another observation can be made from the presented graphs that the region near the TE (AFT-TE) seems to experience less impact pressure, more pronounced at the location of PT\#15.

Using boxplots can indicate how the impact pressures vary amongst multiple runs having approximately an identical wave condition. The variation in impact pressures can be examined by investigating the uncertainty attributed to the transducer itself, its location (which may be affected by side edges) as well as the deck clearance. By studying the three conditions 1,9 and 18 discussed above, the following findings can be reached:

- The transducer uncertainty can be tested as shown in Figure 18 by integrating the pressure with respect to time. As demonstrated above, the impulse pressure defined as integrated pressure does not largely vary among repeated runs.

- Side edges can affect pressure data of transducers located nearby and hence outliers in impact pressures may be introduced e.g. PT\#1, 2 and 15. 
- By reducing the deck clearance the interaction between a steep wave and the structure becomes stronger and more violent resulting in a wider range of impact pressures ( $\max$ and min values in boxplots) and higher standard deviation $(\sigma)$ amongst multiple runs e.g. PT\#4, 5, 6, 8 and 10 when three conditions are compared. To overcome this issue, a sufficient number of repeated runs (seems to be more than five per condition) are required during tanks experiments.

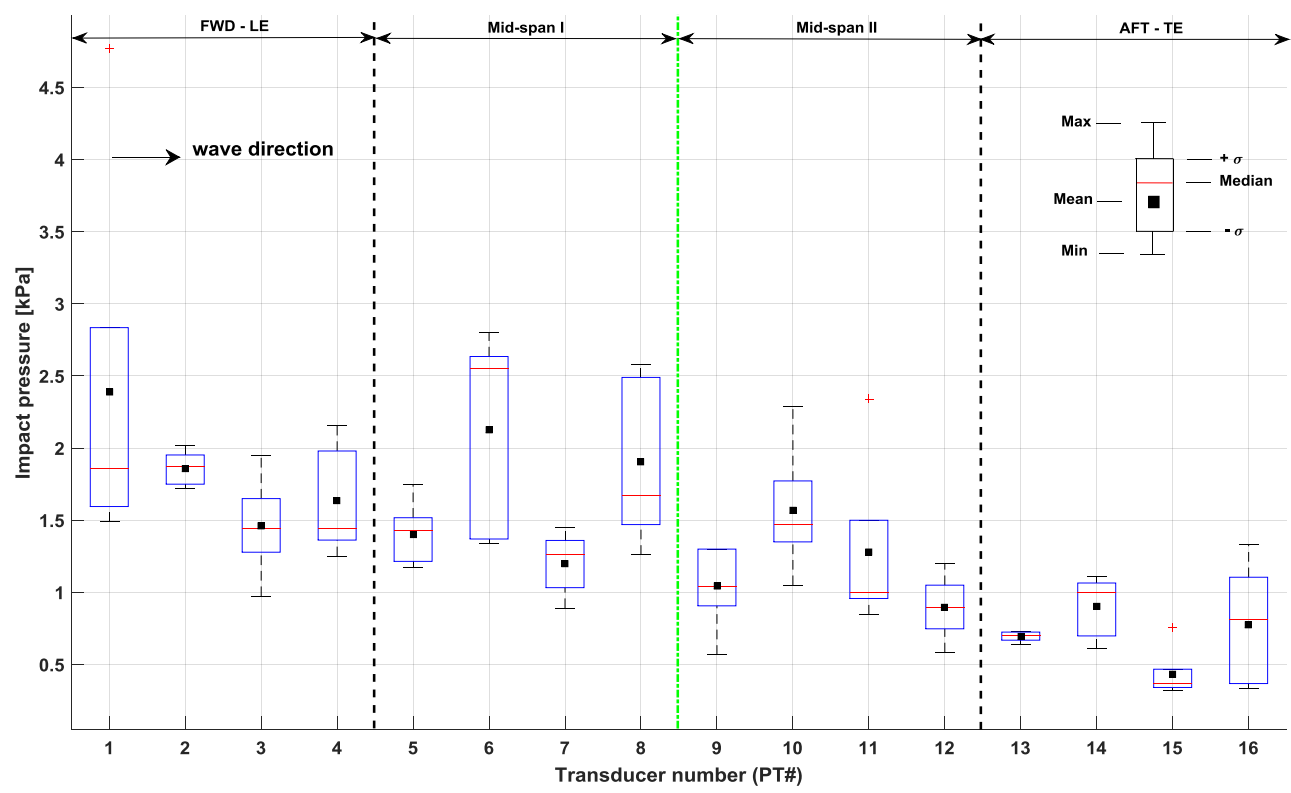

Figure 19. Impact pressures measured by sixteen PTs in multiple runs for condition 1 [WE1 at a $0120 \mathrm{~mm}$ ]. 


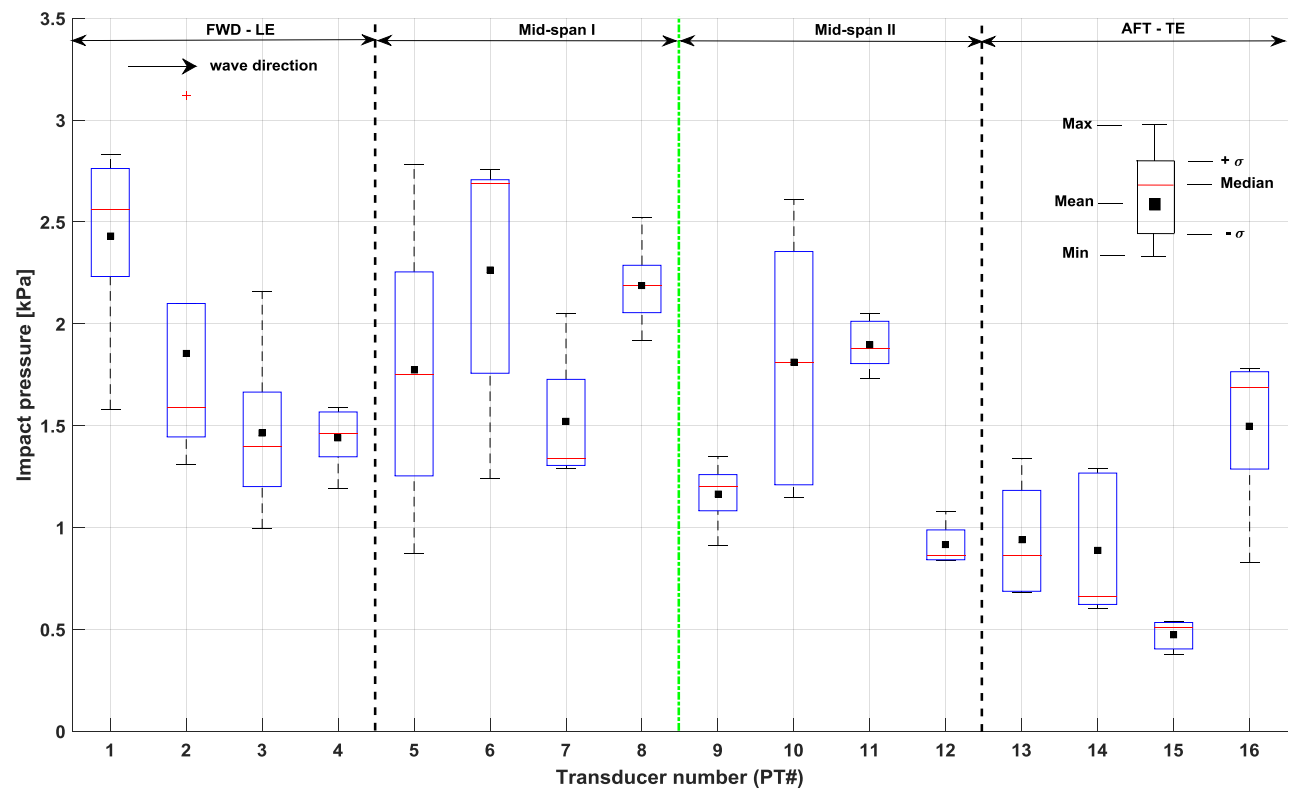

Figure 20. Impact pressures measured by sixteen PTs in multiple runs for condition 9 [WE1 at $\mathrm{a}_{0}=110 \mathrm{~mm}$ ].

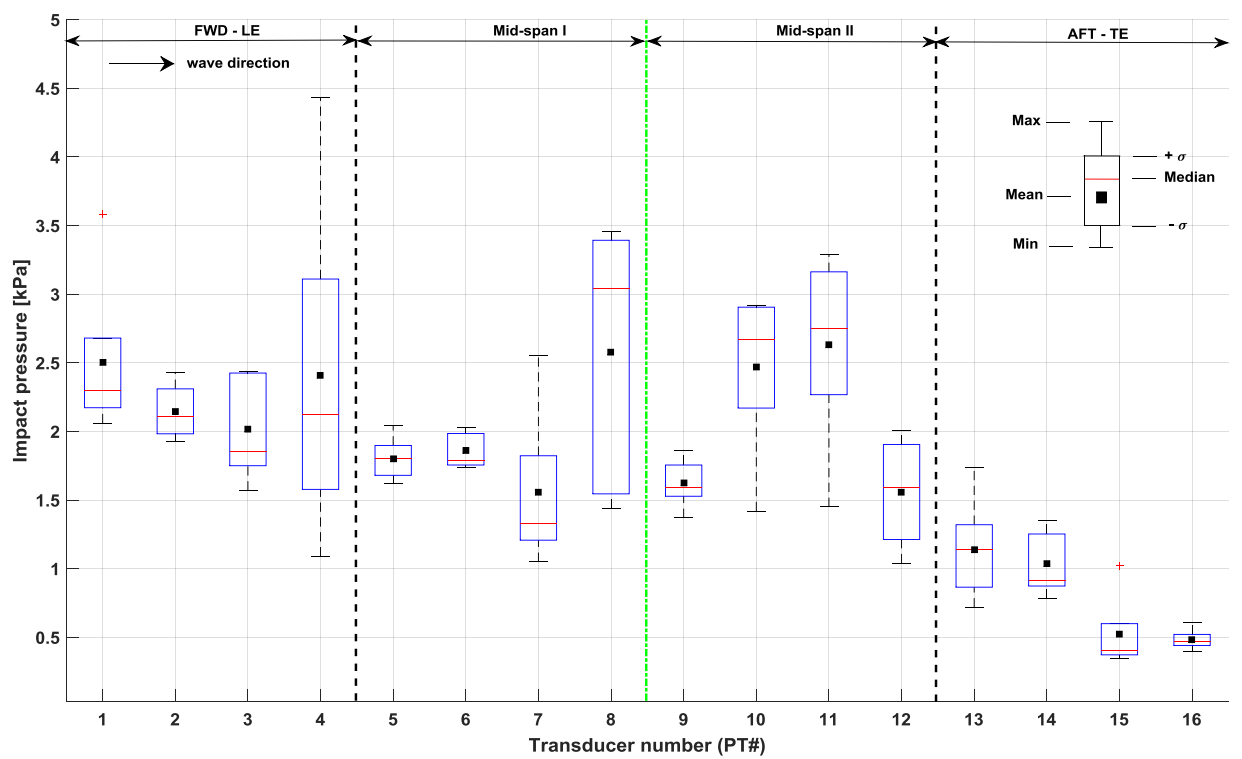

Figure 21. Impact pressures measured by sixteen PTs in multiple runs for condition 18 [WE1 at $\mathrm{a}_{0}=100 \mathrm{~mm}$ ].

\section{Deck clearance versus impact pressures}


The effect of reducing the deck clearance on the impact pressures associated with WE1, 2, 5 and 8 is shown in Figures 22 to 25 . The averaged impact pressure measured by each transducer is normalised by the dynamic pressure $\left(0.5 \rho \mathrm{C}^{2}\right)$ associated with the wave event. The $\mathrm{x}$-position of the sixteen pressure transducers was used as $x$-axis to represent the length of the deck structure (Table 2) where the LE and TE are denoted by vertical dashed lines at $\mathrm{x}=-304 \mathrm{~mm}$ and $\mathrm{x}=304 \mathrm{~mm}$, respectively. The markers represent the number of pressure transducers along the deck (PT\#1 - PT\#16).

A consistent finding can be reached based upon these graphs such that the results confirm that the location of the maximum impact pressure(s) moves towards the trailing edge (TE) as the deck clearance is reduced. Furthermore, the figures suggest that the impact pressure at the deck edges are not clearly affected by reducing the deck clearance e.g. PT\#1, 2 and PT\#15 and 16. For the remaining pressure locations PT\#3 - PT\#14, the effect of $\mathrm{a}_{0}$ is more noticeable. Another observation can be made based on the pressure data such that when the deck clearance was at $120 \mathrm{~mm}$ (original) the structure experienced impact pressures (at most locations) below the associated dynamic pressure of the incoming wave. Whereas the impact pressures experienced by the structure were found to exceed the dynamic pressure as a result of reducing the deck clearance by $10 \mathrm{~mm}$ or $20 \mathrm{~mm}$. 


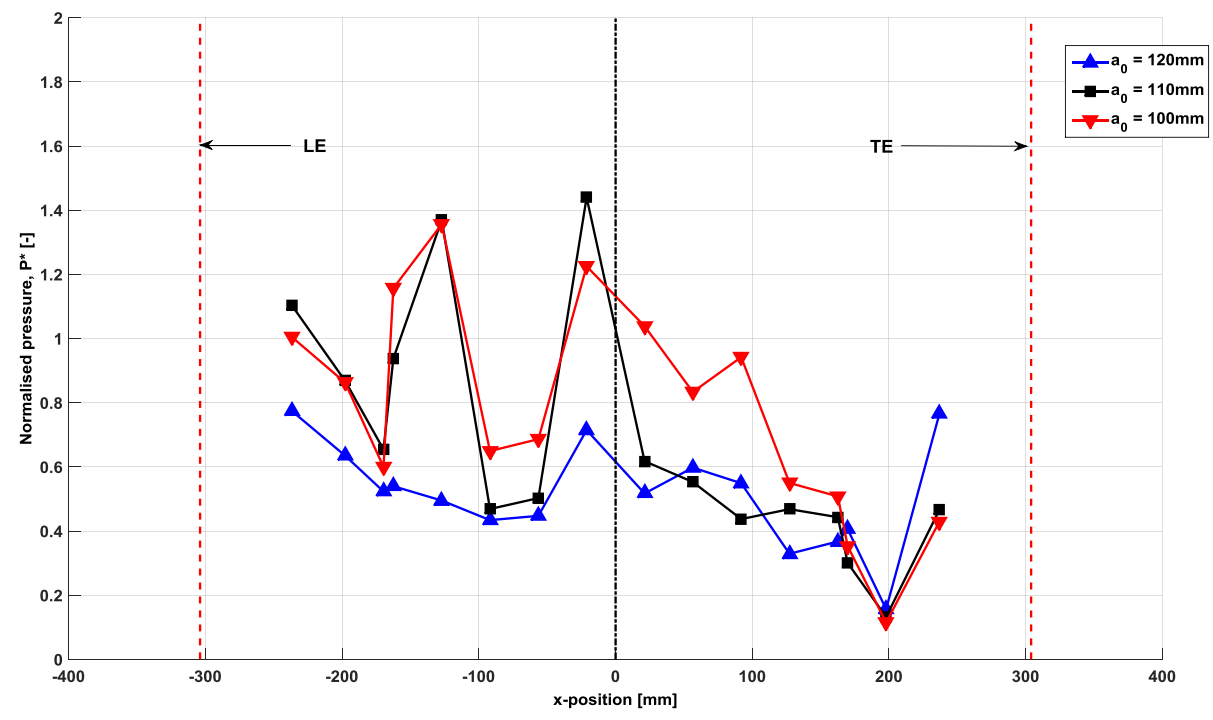

Figure 24. Normalised impact pressures [ $\left.\mathrm{P}^{*}=\mathrm{Pi} / 0.5 \rho \mathrm{C} 2\right]$ associated with WE5 along the bottom plate at different values of $\mathrm{a} 0$.

) when $\mathrm{a}_{0}=120 \mathrm{~mm}$, high pressures were found to be captured by PT\#1, 4, 5 and 8, where the maximum pressure was measured by PT\#1 with a mean value equal to the wave dynamic pressure. When the three deck clearances are compared it can be noted that a similar trend appears for most pressure transducer at same deck clearance, e.g. the forward section experienced high pressures, (at PT\#1, 4 and 8). Likewise, at $\mathrm{a}_{0}=110 \mathrm{~mm}$, higher pressures experienced by the bottom plate at PT\#2, 5 and 8. By reducing the deck clearance to $100 \mathrm{~mm}$, much higher pressures can be seen at PT\#5, 6 and 8. This also implies that the location of higher pressures moves towards the TE as the deck clearance reduces. A total reduction of $20-\mathrm{mm}$ in the deck clearance can result in as much as twice as the slamming pressures (e.g. PT\#5 and 8) experienced by the deck structure at the original deck clearance $(120 \mathrm{~mm})$. The middle between the PT\#5 and the mid-span of the bottom plate seems to be subjected to the large impact pressures when $\mathrm{a}_{0}=100 \mathrm{~mm}$ due to WE8. 


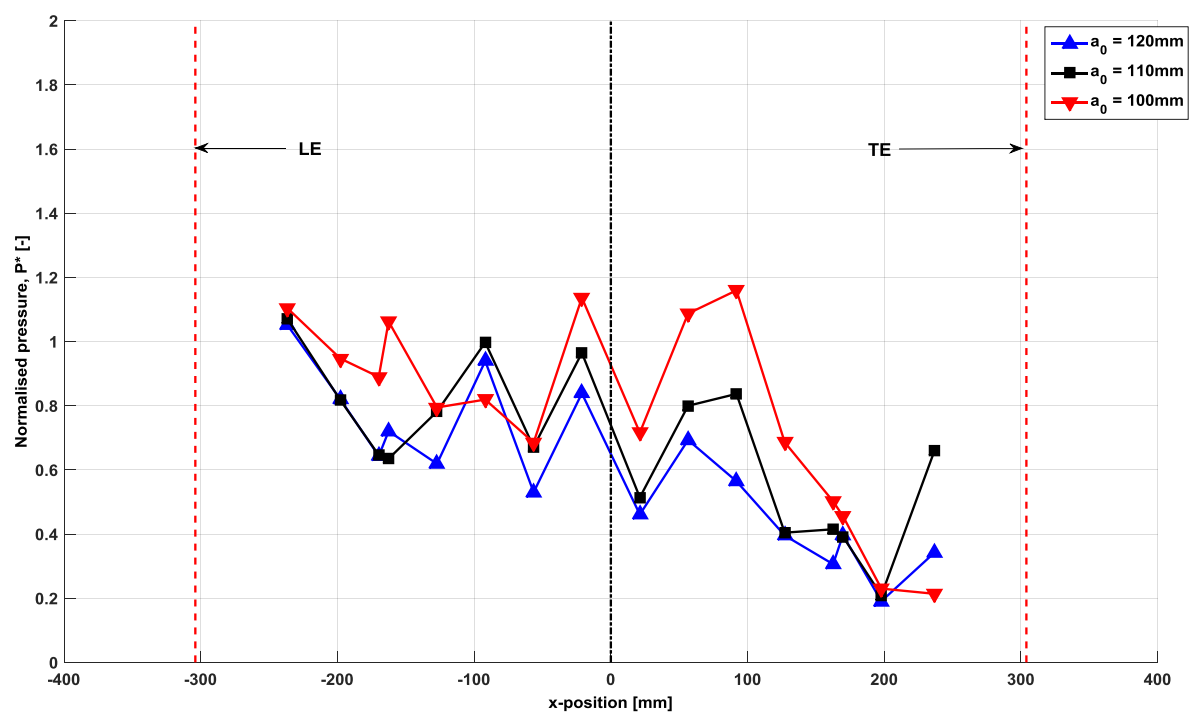

Figure 22. Normalised impact pressures $\left[\mathrm{P}^{*}=\mathrm{P}_{\mathrm{i}} / 0.5 \rho \mathrm{C}^{2}\right]$ associated with WE1 along the bottom plate at different values of $\mathrm{a}_{0}$.

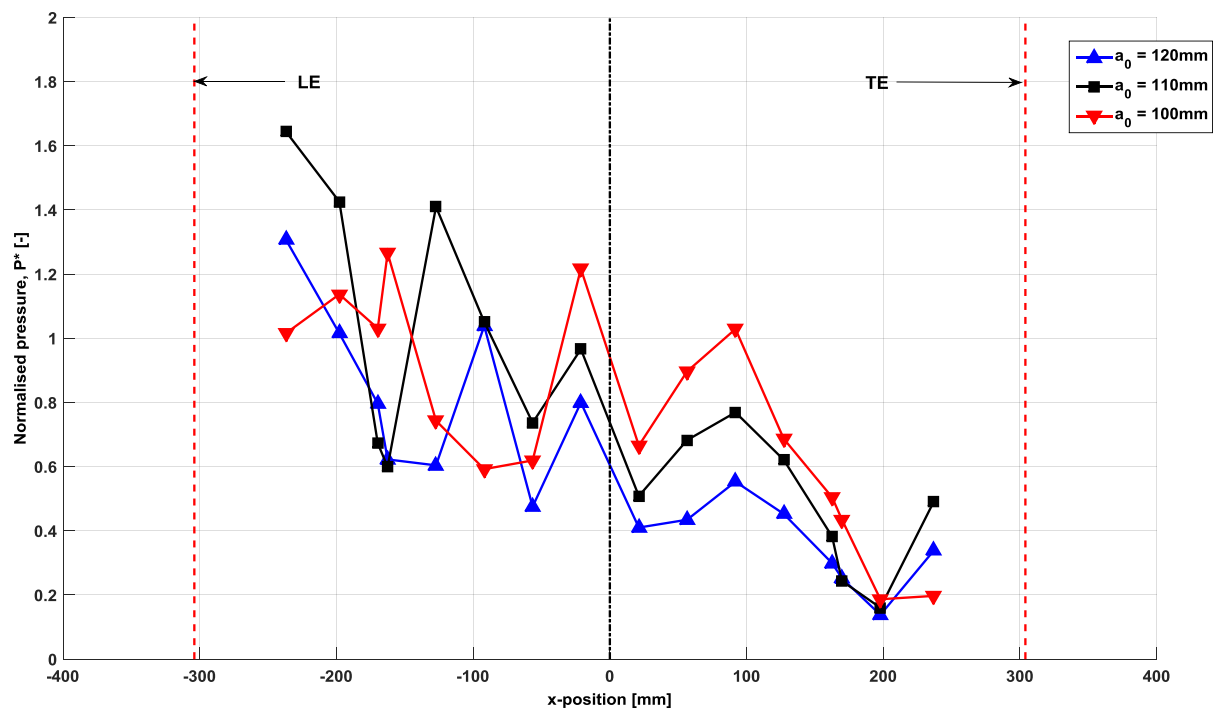

Figure 23. Normalised impact pressures $\left[\mathrm{P}^{*}=\mathrm{P}_{\mathrm{i}} / 0.5 \rho \mathrm{C}^{2}\right]$ associated with WE2 along the bottom plate at different values of $\mathrm{a}_{0}$. 


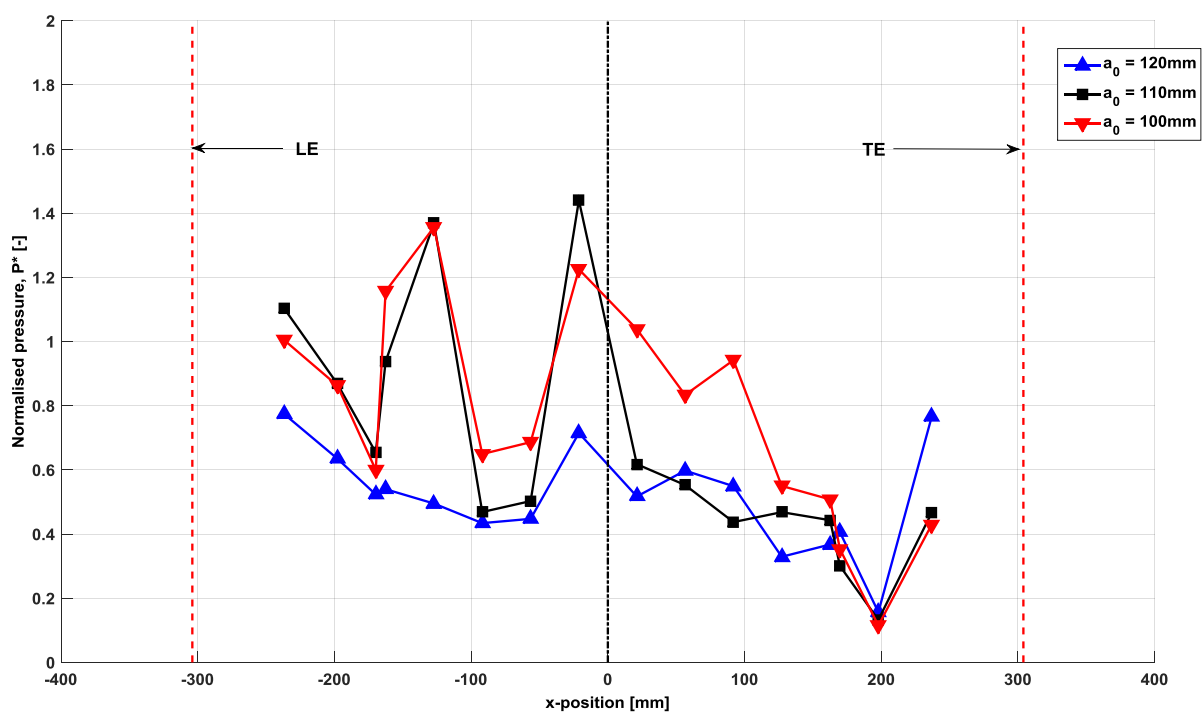

Figure 24. Normalised impact pressures $\left[\mathrm{P}^{*}=\mathrm{P}_{\mathrm{i}} / 0.5 \rho \mathrm{C}^{2}\right]$ associated with WE5 along the bottom plate at different values of $\mathrm{a}_{0}$.

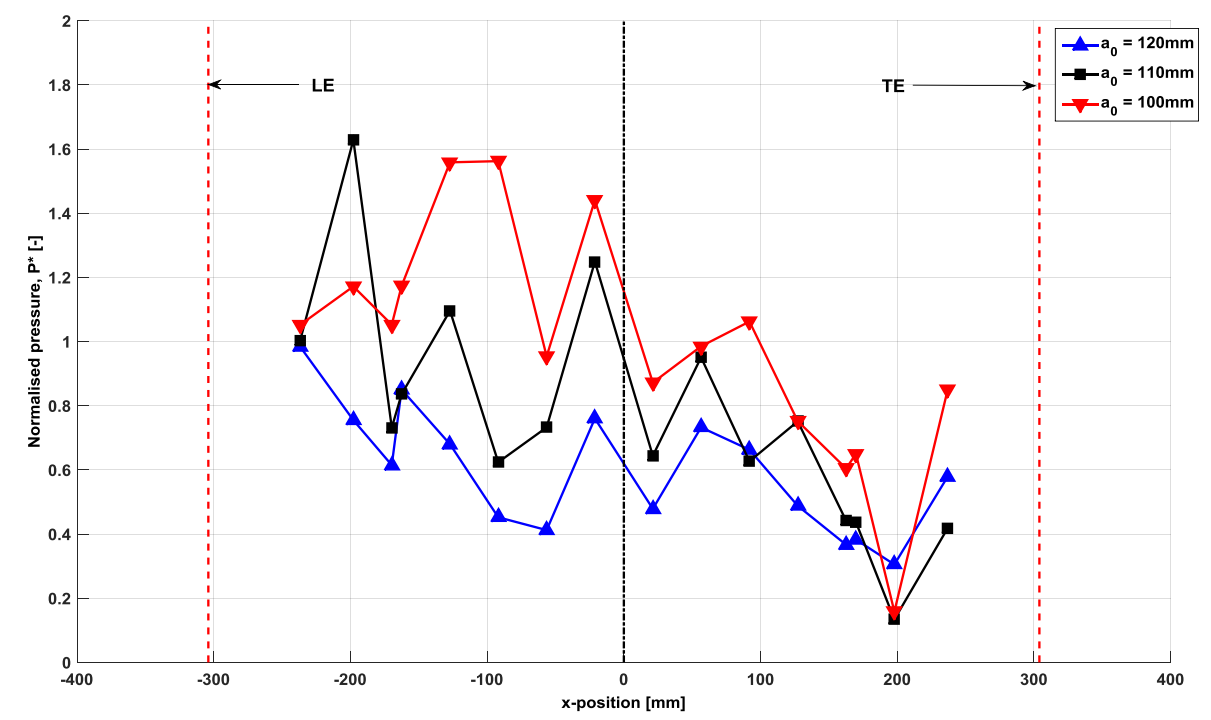

Figure 25. Normalised impact pressures $\left[\mathrm{P}^{*}=\mathrm{P}_{\mathrm{i}} / 0.5 \rho \mathrm{C}^{2}\right]$ associated with WE8 along the bottom plate at different values of $\mathrm{a}_{0}$.

\section{Occurrence time of impact pressures}

For condition 1 (WE1, a $0120 \mathrm{~mm}$ ), the occurrence time of wave slamming at the location of each pressure 
transducer was estimated using the measured pressure signals and the wave elevations. Figure 26 (a) shows the time history of WP4 (LE) and WP5 (TE) in Run 1. The start and the end of WE1 are denoted by $t_{0}$ and $t_{f}$, respectively where $t_{0}$ is to define the initial time in which the wave crest comes into contact with the bottom plate at the LE. The markers in Figure 26 (b) represent the number of pressure transducers along the deck (PT\#1 - PT\#16). The maximum peak pressure (at PT\#8) was found to occur at approximately $130 \mathrm{~ms}(9.5 \%$ $\mathrm{T}_{\mathrm{z}}$ ) from $\mathrm{t}_{\mathrm{o}}$ which is almost equal $\mathrm{x} / \mathrm{C}$, where $\mathrm{x}$ is the distance from the LE to the centre of PT\#8. This indicates that the change of wetted length along the deck can be approximated by the wave phase velocity and/or extracted from pressure data. On average, a time difference of 20 -ms was obtained between two following pressure transducers.
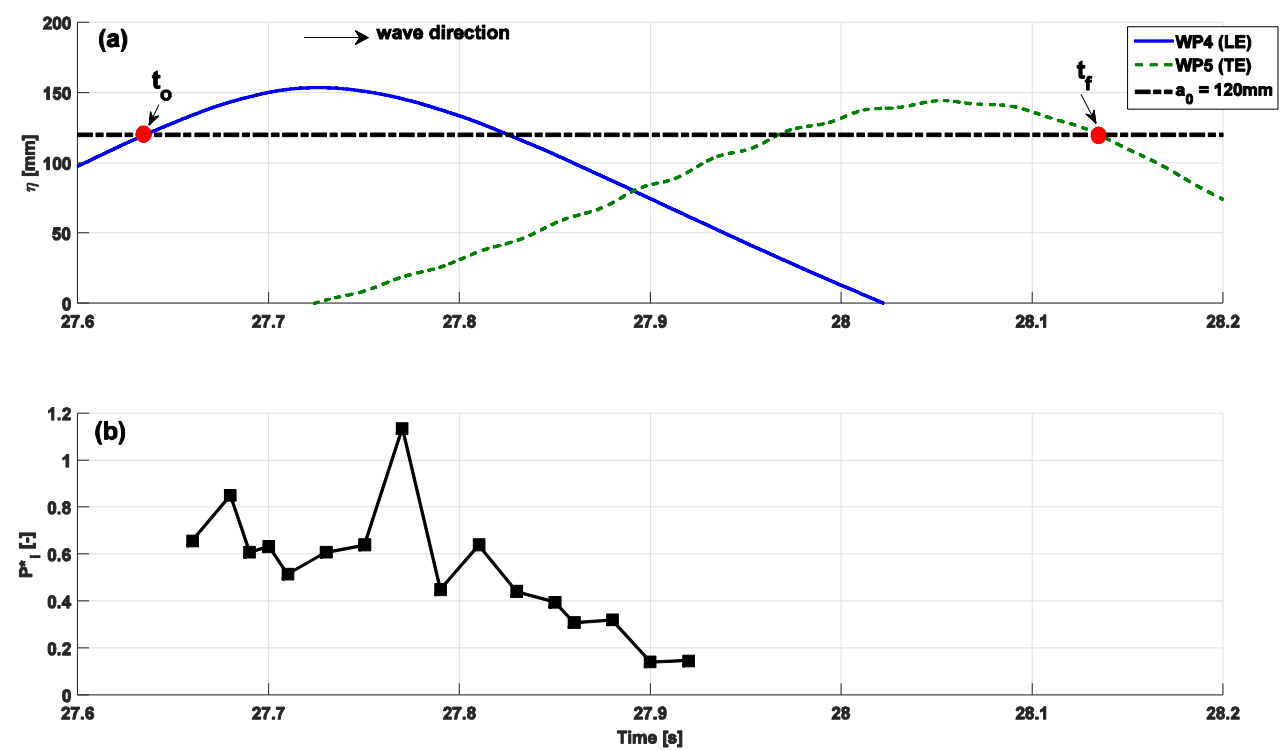

Figure 26. A typical time tracking of impact pressures along and across the bottom plate for condition 1 (WE1, a $a_{0}=120$ $\mathrm{mm}$ ) and associated with Run 1: (a) wave elevation measured by WP4 (LE) and WP5 (TE); (b) loading cycle occurrence time.

\section{Conclusions}

This paper described a series of model tests conducted to examine extreme wave events associated with tropical cyclonic conditions and their impacts on an offshore deck structure. Extreme waves of a representative cyclonic 
sea state were observed in a towing tank within long-crested irregular wave trains. Experimental results presented include global forces and localised slamming pressures acting on a rigidly mounted box-shaped deck, which represents a simplified topside structure of a tension leg platform (TLP). The effect of static set-down on the still-water air gap was investigated by applying an equivalent reduction for the deck clearance. On the basis of the present paper findings, the following conclusions can be drawn:

- In the present investigation, the structural dynamic response was found to have a minimal effect on the peak values of the horizontal force, $F_{x}$, and the upward vertical force, $F_{z}(\uparrow)$, and its influence only being noticeable in the water exit phase. This finding should be considered conclusive provided that there are not successive large waves impacting the structure; in which case, the structural and viscous damping appear to strongly influence the force signals, particularly in the direction of wave propagation.

- It can be appreciated that, in many wave events (e.g. WE1, 2, 5 and 8) the effect of deck clearance reduction on all force components is pronounced.

- It was found that a $20-\mathrm{mm}$ reduction $(2.5 \mathrm{~m}$ full scale) in the original deck clearance can lead to a doubly of the magnitude of the horizontal force, $F_{x}$, and the vertical upward-directed force, $F_{z}(\uparrow)$, components. This large increase in force magnitudes highlights the threat of wave deck impact due to air gap reduction.

- Most of the test conditions demonstrated that the magnitude of the impact pressure varies considerably among repeated runs, even if identical wave condition was used. A sufficient number of repeated runs, more than five runs per test condition, are therefore recommended during tank experiments. In most test conditions, it was found that the front half of the bottom plate (PT\#1 PT\#8) experienced higher pressures than the rear section.

- By investigating the effect of deck clearance on the localised impact pressures, it was found that the reduction in the original deck clearance $(10 \mathrm{~mm}$ or $20 \mathrm{~mm}$ ) can increase the impact pressure magnitude 
at many locations along and across the deck underside. However, pressure measurements revealed that the impact pressure may not necessarily increase for all PT locations with decreasing deck clearance.

- The results suggested that the location of the maximum impact pressure(s) moves towards the trailing edge (TE) as the deck clearance is reduced.

- It is worth mentioning that looking at an area rather than a discrete point will be more useful in assessing the severity of the deck clearance reduction on the local effect of wave-in-deck loading on a fixed platform deck.

\section{Acknowledgement}

The authors would like to acknowledge the assistance from the Australian Maritime College towing tank staff members.

\section{Declaration of conflict of interests}

The authors declare that there is no conflict of interest.

\section{References}

1. ABS. Rules for Building and Classing: Floating Production Installation. Houston, USA: American Bureau of Shipping, 2014.

2. API. Recommended Practice for Planning, Designing and Constructing Fixed Offshore PlatformsWorking Stress Design, 2A-WSD, 2007. American Petroleum Institute, 2007.

3. Kvitrud A, Ersdal G and Leonhardsen RL. On the risk of structural failure on Norwegian offshore installations. Proceedings of ISOPE. Stavanger, Norway2001.

4. Kaiser MJ, Yu Y and Jablonowski CJ. Modeling lost production from destroyed platforms in the 20042005 Gulf of Mexico hurricane seasons. Energy. 2009; 34: 1156-71.

5. Lee S-K, Yu K and Huang SC. CFD Study of Air-Gap and Wave Impact Load On Semisubmersible Under Hurricane Conditions. The ASME 33rd Int Conf on Ocean, Offshore and Arctic Eng, OMAE. San Francisco, CA, USA: ASME, 2014.

6. NOPSEMA. Annual Report by National Offshore Petroleum Safety and Environmental Management Authority. Australia: NOPSEMA, 2013.

7. Nezamian A and Altmann J. An Oil Field Structural Integrity Assessment for Re-Qualification and Life Extension. The ASME 32nd Int Conf on Ocean, Offshore and Arctic Eng, OMAE. Nantes, France: ASME, 2013.

8. O’Connor P, Bucknell J, DeFranco S, Westlake H and Puskar F. Structural Integrity Management (SIM) of offshore facilities. Offshore Technology Conference, OTC 17545. Houston, USA: Offshore Technology Conference, 2005. 
9. Naess A and Gaidai O. Extreme value statistics of non-Gaussian random wave fields and the airgap problem for offshore platforms. The 8th International Conference on Structural Dynamics, EURODYN 2011. Leuven, Belgium2011.

10. Mansour A, Gordon BJ, Ling Q and Shen Q. TLP Survivability against Progressive Failure of Tendon and Foundation Systems in Offshore Western Australian Harsh Environment. The ASME 32nd Int Conf on Ocean, Offshore and Arctic Eng. Nantes, France: ASME, 2013.

11. BOM. Report on Cyclone Orson - April 1989, Bureau of Meteorology. Australia1992.

12. Buchan S, Black P and Cohen R. The Impact of Tropical Cyclone Olivia on Australia's Northwest Shelf. Offshore Technology Conference. Houston, USA: Offshore Technology Conference, 1999.

13. Raaij Kv. Dynamic behaviour of jackets exposed to wave-in-deck forces. Mech and Struct Eng and Material Scien. Stavanger, Norway: University of Stavanger, 2005.

14. Scharnke J, Vestbostad T, Wilde Jd and Haver SK. Wave-In-Deck Impact Load Measurements on a Fixed Platform Deck. The ASME 33rd Int Conf on Ocean, Offshore and Arctic Eng, OMAE. San Francisco, CA, USA: ASME, 2014.

15. Broughton P and Horn E. Ekofisk Platform 2/4C: Re-analysis due to subsidence. ICE Proceedings. Ice Virtual Library, 1987, p. 949-79.

16. Iwanowski B, Grigorian H and Scherf I. Subsidence of the Ekofisk Platforms: Wave in Deck Impact Study-Various Wave Models and Computational Methods. The ASME 21st Int Conf on Ocean, Offshore and Arctic Eng, OMAE. Oslo, Norway: ASME, 2002.

17. Winsor F. Evaluation of methods to remove inertial force from measured model wave impact force signals. Ocean engineering. 2002; 30: 47-84.

18. Hirdaris SE, Bai W, Dessi D, et al. Loads for use in the design of ships and offshore structures. Ocean engineering. 2014; 78: 131-74.

19. El Ghamry O. Wave forces on platform decks. Offshore Technology Conference. Dallas, USA: Offshore Technology Conference, 1971, p. 537-48.

20. Kendon TE, Pakozdi C, Baarholm RJ, Berthelsen PA, Stansberg C-T and Enger S. Wave-in-deck impact: Comparing cfd, simple methods, and model tests. The ASME 29th Int Conf on Ocean, Offshore and Arctic Eng. American Society of Mechanical Engineers, 2010, p. 495-509.

21. Ding Z, Ren B, Wang Y and Ren X. Experimental study of unidirectional irregular wave slamming on the three-dimensional structure in the splash zone. Ocean Engineering. 2008; 35: 1637-46.

22. Ren B and Wang Y. Experimental study of irregular wave impact on structures in the splash zone. Ocean Engineering. 2003; 30: 2363-77.

23. Iwanowski B, Lefranc $M$ and Wemmenhove R. CFD simulation of wave run-up on a semi-submersible and comparison with experiment. The ASME 28th Int Conf on Ocean, Offshore and Arctic Eng. ASME, 2009.

24. Almeland I, Gaul T, Pettersen D and Vogel H. Snorre TLP configuration and analysis technology. Offshore Technology Conference. Houston, USA: Offshore Technology Conference, 1991.

25. Abdussamie N, Thomas G, Amin W and Ojeda R. Wave-in-Deck Forces on Fixed Horizontal Decks of Offshore Platforms. The ASME 33rd Int Conf on Ocean, Offshore and Arctic Eng, OMAE. San Francisco, CA, USA: ASME, 2014.

26. Abdussamie N, Amin W, Ojeda R, Thomas G and Drobyshevski Y. Irregular Wave Generation and Assessment of Static Air Gap of Offshore Structures. the 19th Australasian Fluid Mechanics Conference. Melbourne, Australia: AFMS, 2014.

27. Olagnon M, Nerzic R and Prevosto M. Extreme water level from joint distributions of tide, surge and crests: a case study. Proc Int Offshore Polar Eng Conf. 1999, p. 95-100.

28. Abdussamie N, Amin W, Ojeda R, Thomas G and Drobyshevski Y. Vertical Wave-in-Deck Loading and Pressure Distribution on Fixed Horizontal Decks of Offshore Platforms. The 24th Int Offshore and Polar Engineering. Busan, South Korea: ISOPE, 2014.

29. DNV. Recommended practice DNV-RP-C205: environmental conditions and environmental loads. Hovik, Norway: Det Norske Veritas, DNV. 2010. 
30. van Dijk R and van den Boom H. Full scale monitoring marco polo tension leg platform. ASME 2007 26th International Conference on Offshore Mechanics and Arctic Engineering. American Society of Mechanical Engineers, 2007, p. 915-21.

31. Kaplan P, Murray J and Yu W. Theoretical analysis of wave impact forces on platform deck structures. Offshore Technology Conference Houston, USA1995.

32. Baarholm R. Experimental and Theoretical Study of Three-Dimensional Effects on Vertical Wave-in-Deck Forces. The ASME 28th Int Conf on Ocean, Offshore and Arctic Eng, OMAE. Honolulu, Hawaii, USA: ASME, 2009.

33. Oberlies R, Khalifa J, Huang J, et al. Determination of Wave Impact Loads for the Hebron Gravity Based Structure (GBS). The ASME 33rd Int Conf on Ocean, Offshore and Arctic Eng. American Society of Mechanical Engineers, 2014.

34. Bhat SS. Wave slamming on a horizontal plate, MSc thesis. Civil Engineering. University of British Columbia, 1994.

35. Murray J, Winso F and Kaplan P. Impact forces on a jacket deck in regular waves and irregular wave groups. Offshore Technology Conference. Houston, USA: Offshore Technology Conference, 1997.

36. ISO. Petroleum and natural gas industries-fixed steel offshore structures, International Organization for Standardization. . In: Organization IS, (ed.). ISO 19902. 2007.

37. Cooker M. The interaction between steep water waves and coastal structures, PhD Thesis. University of Bristol, 1990. 